Review

\title{
General Aspect and Current Fluid Therapy in Cattle with Digestive Diseases
}

\author{
${ }^{1}$ José-Ramiro González-Montaña, ${ }^{2}$ María-José Martin and ${ }^{1}$ Pilar Alonso \\ ${ }^{1}$ Medicine, Surgery and Anatomy Veterinary Department, Veterinary Faculty, \\ University of León, 24071 León, Spain \\ ${ }^{2}$ Department of Animal Science, University of Lleida, 25198, Lleida, Spain
}

Article history

Received: 01-04-2017

Revised: 18-05-2017

Accepted: 30-06-2017

Corresponding Author: José-Ramiro GonzálezMontaña

Medicine, Surgery and

Anatomy Veterinary

Department, Veterinary

Faculty, University of León,

24071 León, Spain

E-mail: jramirogonzalez@unileon.es

\begin{abstract}
Digestive disorders therapy, both in calves and adult animals depends on the correction of dehydration, academia and the removal of Dlactate from the blood and it is possible to do it by means of fluid therapy. To do this, it is necessary to evaluate the dehydration of the animals and to evaluate some clinical signs that allow to suspect acid-base and electrolytes modifications in blood. The exact determination of these alterations, even a field level, by means of portable auto analyzers allow a fluid therapy adapted to each animal. Academia, with accumulation of D-lactate in the blood, seems to be one of the most important factors in the pathogenesis of systemic signs of neurological dysfunction, including ataxia, weakness and reduction of food intake in several digestive diseases in ruminants. Also reviewed are the products available in the market frequently used in the fluid therapy of these diseases, with their main indications and disadvantages. Finally, we review the main digestive pathologies that suffered from ruminants, especially diarrhea in calves, with their treatment.
\end{abstract}

Keywords: Fluid Therapy, Ruminant, Digestive Disorders, Acidosis

\section{Introduction}

While the use of fluid therapy (oral or parenteral) is widespread in pets, in farm animals its use is much less frequent. This is mainly due to two reasons, first practical difficulty to perfuse large volumes of liquid under field conditions (fluids are administered in onfarm) and second the high cost, not so much in the cost of the fluids but in the cost of their application by professional veterinary surgeons (Grove-White, 1994) which in many cases exceeds the value of the animals. Although parenteral administration and especially the difficulty in slow and prolonged intravenous infusions is another noteworthy feature, currently the availability of commercial products which are suited to the veterinary practice and the greater dedication to the clinic in ruminants, compel a review of the therapeutic approach in various intestinal diseases that require fluid therapy, bringing it closer to that which takes place in the clinic of small animals and in humans.

Before discussing the current state of fluid therapy, it is appropriate to recognize how advances in fluid therapy have improved the outcome for survival in different livestock diseases. In recent years, it has increased the survival in neonatal calves, lambs and in adult cows. Probably improvements in oral and
Intravenous (IV) therapy are likely partly responsible for the reduction in mortality rates.

This article does not have the commitment to review the matter in depth, but it will try to give some general aspects of fluid therapy in ruminants, mainly trying to raise a practical approach and bring these concepts to the particularities to take into account the digestive process affecting these animals. We must not forget that some diseases, such as ruminal acidosis and diarrhea in calves are major causes of mortality in ruminants (Naylor et al., 2006) and that the positive resolution of the pathology depends not only on the etiological treatment but also on the adequate restoration of fluid and electrolytes in the dehydrated animal.

\section{General Plan of Fluid Therapy in Ruminants Factors to Consider}

The physiological state in the animal organism depends on the balance of fluids and electrolytes and this, in turn, depends on an external balance, represented by the relationship between the mechanisms intake/absorption and removal/secretion; and an inner balance, related to the distribution of fluids between compartments body (intracellular and extracellular fluid, which is subdivided in plasma, interstitial fluid/lymph and transcellular fluid) (Lisboa, 2004). 
The general objectives of the fluid therapy are 1. To replace lost fluids and correct existing electrolyte imbalances, 2. To cover the animal's needs in fluid maintenance and electrolytes and 3. To solve the acidbase disturbances that have occurred (Rejas and Alonso, 2008; Grove-White, 1994). In ruminants, with a gastrointestinal disease, the goals of fluid therapy, in addition to the aforementioned objectives (to correct the deficit fluid, the electrolyte imbalance and the acid-base imbalances) should be aimed at reducing concentrations of D-lactate (Naylor et al., 2006; Grove-White, 1994).

On the other hand, in the dehydrated animals, it is important to restore the hydro-sodium balance, which helps the implementation of the homeostatic mechanisms of the body, particularly the kidney. We mustn't forget that if the kidneys are adequately perfused they are able to control mild to moderate acidosis and alkalosis (Rejas and Alonso, 2008).

Success in fluid therapy depends on the proper choice of the volume to perfuse, the route of administration, the rate of infusion, the type of fluid administered and the duration of the treatment (Lisboa, 2004; Naylor et al., 2006; Rejas and Alonso, 2008).

\section{Calculating Total Fluid Requirements}

To calculate the total amount of fluids to be administered 3 different volumes must be taken into consideration: 1. Volume replacement, which is the amount of lost fluid, which are valued based on the degree of dehydration, 2. Daily maintenance needs or volume maintenance, 3. Volume of expected losses (mainly via faeces) (Rejas et al., 2001; Lisboa, 2004; Rejas and Alonso, 2008):

\section{Volume of Replacement}

Is one that corrects the fluid deficit in the animal (with a small margin of error). It is calculated by multiplying the estimated dehydration (in percent) by body weight (in kilograms) and ideally should be replaced quickly. It should be recalculated every $24 \mathrm{~h}$ of treatment. It is calculated by the following formula: (Lisboa, 2004; Smith and Berchtold, 2014).

$$
\begin{aligned}
& \text { Replacement Volume }(L)=\text { Body Weight } \\
& (\mathrm{kg}) \times \text { Dehydration Degree (\%) }
\end{aligned}
$$

\section{Volume of Maintenance}

Takes into account the daily rate of replacement of liquid (or water) in the body and varies with the age of the patient. The volume is calculated from a number of formulas; mainly depending on the affected species and its age and to be administered within $24 \mathrm{~h}$ of treatment. Therefore, unlike the volume substitution, the administration is slow and should be divided throughout the day (Lisboa, 2004; Rejas et al., 2001). In cattle it varies from $50 \mathrm{~mL} \mathrm{~kg}^{-1}$ body weight per day in adults, to
$100 \mathrm{~mL} \mathrm{~kg}^{-1}$ in young animals and $150 \mathrm{~mL} \mathrm{~kg}^{-1}$ in new born animals, it depends significantly on the animal's age (Lisboa, 2004; Rejas et al., 2001).

$$
\begin{aligned}
& \text { Volume of Maintenance }(\mathrm{ml})=(50-150 \\
& \left.\left.\mathrm{mL}^{-1}\right) \times B W \text { (body weight, } \mathrm{kg}\right)
\end{aligned}
$$

\section{Volume of Expected Losses}

Takes into account the volume that continues to be lost throughout the day of the treatment. It is difficult to measure; it is an estimated amount and therefore with a relatively wide margin of mistake and it is only possible in those diseases in which the loss is visible (diarrhea and polyuria). It is impossible to estimate in cases of fluid abduction (abomasal dilatation, intestinal obstruction, etc.), so the technical difficulties cause this volume to be, in some cases, ignored (Lisboa, 2004).

\section{Assess the Degree of Dehydration Evaluation and Diagnosis of Acidosis}

Therefore, to calculate the amount of fluids to be administered and regardless of the infusion line, the first step is to assess the degree of dehydration, which will calculate the volume of replacement.

The key for ruminant clinic as is being able to decide whether the fluid therapy is necessary in sick calves, based more on the clinical examination rather than on the laboratory values. The most important clinical parameters to guide decision-making in fluid therapy is obtained from the evaluation of the hydration status (perhaps it would be better to say the degree of dehydration) and the functioning of the Central Nervous System (CNS) (Smith and Berchtold, 2014).

Competence to assess hydration status is one of the critical points and often the calculation of the appropriate volume of fluids for treatment depends on the judgment of the clinician to accurately establish the degree of dehydration that the sick animal show. This judgment is based on the identification of a series of signs, some subjective and therefore are not always quantifiable criteria. The error can be reduced considerably when a specific set of symptoms is evaluated instead of one of them in particular (Lisboa, 2004). Another possibility, though not always possible in the buiatrics, is to measure hematocrit and plasma protein concentration; this makes it possible to calculate with less chance of error the degree of dehydration. The increase in the value of the corpuscular volume (hematocrit) and the plasma protein concentration would be indicative of laboratory findings and could confirm dehydration (Lisboa, 2004).

The degree of dehydration can be assessed on clinical grounds using signs such as the sinking of the eye (enophthalmos) and skin tenting, mainly the elasticity of the skin over the neck and thorax, by the color and dryness of the membranes mucous membranes (Table 1 and 2) (Rejas et al., 2001; Naylor et al., 2006; 
Grove-White, 1994; Smith, 2009). The bulging of the skin on the eyelid is a reliable indicator of dehydration (Constable et al., 1998; Naylor et al., 2006). According to Smith and Berchtold (2014), the degree of enophthalmos is the best predictor of dehydration in calves, followed by skin elasticity in the neck and chest. In contrast to Rejas and Alonso (2008), in addition to the degree of hydration, the eye position within the orbit depends on the amount of body fat, so in the case of cachectic animals or those with chronic diarrhea it is recommended the use of the cervical fold as the most reliable indicator of the degree of hydration (Rejas and Alonso, 2008). Constable (2003) recommends multiplying the ocular collapse (in $\mathrm{mm}$ ) by 1.7 to estimate the degree of dehydration. In clinically sick calves is important to assess the hydration status along with other clinical signs, among which it should be taken into account the ability of the calf to suckle, the severity of CNS depression and if it can stand up (degree of weakness) Smith and Berchtold (2014). The set of symptoms indicated, are more visible in young animals and are specially identified and characterized in calves affected by diarrhea (Lisboa, 2004).

However, in Naylor et al. (2006)'s opinion many of the older schemes used to assess dehydration have overemphasized the severity of dehydration, as has been shown in multiple clinical trials.

In practical terms, it is considered that below $5 \%$ of dehydration there are no clinical signs and above $12 \%$ there is a risk of death. Based on this, you can categorize in mild dehydration (5-8\%), moderate (8-10\%) and severe $(>10 \%)$.

\section{Mild Dehydration (5 to $8 \%$ of $B W$ )}

The animal shows discreet apathy, remains standing, it maintains its thirst and appetite (i.e., the sucking reflex), it has decreased skin elasticity (2-4"), with pink hardly sticky mucous, Capillary Refill Time (CRT) is 23" (Lisboa, 2004; Smith, 2009).

\section{Moderate Dehydration (8 to $10 \% \mathrm{BW}$ )}

Show severe apathy, they prefer sternal recumbency (although they can get up unassisted), with anorexia (the sucking reflex is still present), with low skin elasticity (5"), it has dry red sticky mucus, with a retraction of the eyeball (enophthalmos), tachycardia and weak and regular pulse, cold extremities and discreetly CRT: 4-5" (Lisboa, 2004; Smith, 2009).

\section{Severe Dehydration (10 to $12 \% \mathrm{BW}$ )}

Depression, sternal recumbency permanent, loss of appetite (lack of sucking reflex), very low skin elasticity (6-10") and dry red mucous membranes, marked enophthalmos, cold extremities, hypothermia, tachycardia and thready pulse and CRT $=6-8 "$ (Lisboa, 2004; Smith, 2009).

\section{Hypovolemic Shock (12\% BW)}

Coma, decubitus lateral permanent, loss of appetite (reflex suction absent), lack of skin elasticity (up to 20"), dry mucous with a whitish or bluish colour, enophthalmos marked, tachycardia or bradycardia, arrhythmia, thready pulse, hypothermia and cold extremities, CRT>8" (Lisboa, 2004; Smith, 2009).

Silanikove (1991) cites some goat's dehydration around $20 \%$ (range $16-22 \%$ ) of their initial mass and the goats always restored their initial mass $(+1 \mathrm{~kg})$ when given access to water.

Guidelines for estimating dehydration are shown in Table 1 and 2.

The severity of acidosis cannot be determined on clinical ground, nor is it related to the degree of dehydration present (Grove-White, 1994).

The evaluation and diagnosis of acidosis from clinical signs is common in bovine veterinary practice. The accuracy of predicting the degree of acidosis taking into account the clinical signs has varied between studies. Clinical signs of neurological depression weakness, ataxia and decreased reflexes in threatening situations and for breastfeeding and the panicular reflex) are highly correlated with the severity of metabolic acidosis in calves without dehydration. Also in diarrheic calves, signs of CNS depression, the ability to stand and the suction force correlate well with metabolic acidosis (Smith and Berchtold, 2014). The degree of enophthalmos and peripheral skin temperature are important and obvious signs that determine whether or not IV fluid therapy is indicated; however, they do not correlate with the degree of acidosis (Smith and Berchtold, 2014).

While dehydration should be assessed from clinical signs as indicated above, the acid-base status can, however, be simply and quickly measured using an analyser apparatus. Today this equipment is portable and not too expensive equipment (Grove-White, 1994), it measures the total carbon dioxide $\left(\mathrm{tCO}_{2}\right)$ from a blood sample, it is important to remember that the main source of carbon dioxide continues to be the plasma bicarbonate. Blood gases and acid-base status are ideally determined with a portable gas analyser blood, such as i-STAT System (Abbott Point of Care Inc., Princeton, NJ) (Smith and Berchtold, 2014). However, sometimes these laboratory analysers are expensive, are not available for clinical veterinarians and therefore are not used in most clinical cases.

Experimental studies using IV diuretics and orally administered sucrose shows that calves can suffer dehydration of at least $14 \%$ loss of body weight without becoming deeply depressed or lose the ability to stand or suck. As in naturally occurring diarrhea, most fluid loss is from the extracellular space. Despite the severe dehydration there were only minor changes in blood $\mathrm{pH}$; levels of L-lactate increased from 1.1 to $2.8 \mathrm{mmol} \mathrm{L}^{-1}$ (Constable et al., 1998). 
Table 1. Clinical signs for guide to assessment of fluid losses in the calves

\begin{tabular}{llllll}
\hline & & & Skin tent & Mucous & \\
Dehydration & Demeanor & Eyeball recession & duration $(\mathrm{sec})$ & membranes & Extremities \\
\hline$<5 \%$ & Normal & None & $<2$ & Moist, pink & Temperate \\
$6-8 \%($ mild $)$ & Slightly depressed & Slight, $1-3 \mathrm{~mm}$ & $3-5$ & Dry & - Temperate at \pm Cold \\
$8-10 \%$ (moderate) & Depressed & Moderate, $4-5 \mathrm{~mm}$ & $6-7$ & Dry & \pm Cold at cold \\
$10-12 \%$ (severe) & Comatose & Severe, $6-7 \mathrm{~mm}$ & $8-10$ & Very Dry & Cold \\
$>12 \%$ & Comatose/dead & Severe, $8-12 \mathrm{~mm}$ & $>10$ & Very Dry & Cold \\
\hline
\end{tabular}

Table 2. Clinical assessment of dehydration in cows (Rejas et al., 2001), * some calves may lose up to 16\% BW (Naylor et al., 2006)

\begin{tabular}{ll}
\hline Dehydration (\% loss BW) & Clinical signs \\
\hline $0-5 \%$ & Not detectable \\
$6-7 \%$ & Mild enophthalmos \\
& Persistence skinfold $(3-5$ sec.) \\
$8-9 \%$ & Dry mucous \\
& Hollow eyes \\
$10-12 \%$ & Persistence skinfold $(6-10$ sec.) \\
& Sticky mucous \\
& Deep-set eyes in the orbits \\
$12-15 \%$ & Skin fold indefinite persistence $(>15$ sec.) \\
& Dry mucous \\
& Clearly depression \\
& Marked signs of shock \\
\hline
\end{tabular}

By contrast, a case study of naturally occurring severe calf diarrhea showed that most deeply depressed calves were involuntary lateral decubitus with and had an average level of $7.5 \%$ dehydration; and only a few calves were more than $14 \%$ dehydrated (Naylor, 1999). The discrepancy between the degree of dehydration commonly seen in the field and the maximum amount of dehydration that a calf can support reflects the influence of other factors working along with dehydration to limit life. For example, many calves are also acidotic dehydrated and this combination is likely to be more lethal than dehydration alone (Naylor et al., 2006).

Dehydration is a common feature of ruminal acidosis in calves (Halimi et al., 1991; Gentile et al., 2004). In acidosis and the dehydration syndrome the clinical signs of dehydration are not present. However, serum creatinine concentrations may be elevated suggesting renal failure. This may be secondary to mild hypovolemia and decreased renal blood flow (Kasari and Naylor, 1986; Naylor et al., 2006).

\section{Choice of Route And Rate of Administration Orally or Parenterally?}

\section{Orally or Parenterally?}

The level of dehydration indicates the way to apply the fluid therapy. In diarrheic young animals, when dehydration does not exceed $8 \%$ and there is adequate tissue perfusion, the oral route may be sufficient. These cases, with mild dehydration $(<6 \%)$ or moderate (between 6 and $8 \%$ ) with intestinal motility and intact intestinal epithelium, are candidates for enteral rehydration (Rejas et al., 2001; Rejas and Alonso, 2008). However, if dehydration is severe $(>8 \%)$ it is mandatory the intravenous route, supplemented in some cases with oral rehydration. It is necessary to note that very dehydrated calves often do not suck and have ileus, delaying the absorption of oral liquids (Rainger and Dart, 2006; Rejas and Alonso, 2008).

Also for signs of shock (poor perfusion) require the use of the intravenous route; while signs such as enophthalmos, mucous dryness or increased duration of the skinfold only indicate dehydration. Signs include hypothermia, coldness of limbs, ears and tail, decubitus, tachycardia, weak pulse, increased capillary refill time, pale mucous, CNS depression, whether or not they can stand (degree of weakness) and absence of sucking reflex indicate that the animal is shocked or even about to go into shock (Rejas and Alonso, 2008; Smith and Berchtold, 2014).

\section{Oral Rehydration}

Parenteral fluid therapy should be set up for any animal with an imbalance in fluid, electrolytes or acid-base and for those in which oral fluid therapy is unlikely to be effective. However if oral hydration is set up from the beginning, before any deficits and imbalances become too severe, this treatment is highly effective in most cases of calves with diarrhea. However, it will be totally ineffective in recumbent or comatose calves, as they are likely to be suffering from shock or severe acidosis. Parenteral fluid therapy is also indicated in diarrheic calves, which progressively worsen despite adequate oral treatment (Rainger and Dart, 2006; Grove-White, 1994). 
The oral route is the best solution for administrating a rehydrating solution when the calf retains the sucking reflex which rules out significant dehydration (Alonso et al., 2001; McClure, 2001; Rainger and Dart, 2006; Smith, 2009; Meganck et al., 2014). This also has other advantages as the solution can be administered by the farmer avoiding early degrees of severe dehydration, a large quantity of rehydrating solution may be rapidly administered without the risk of side effects, it is possible to administer high amounts of potassium without toxic risk; and even in most cases they are cheaper than intravenous solutions (Rejas et al., 2001; Alonso et al., 2008a). They also have some drawbacks, since they are not suitable in animals whose intestinal mucosa is much deteriorated, exacerbating diarrhea if they do not absorb glucose; and they are not valid in animals with severe signs of dehydration (Alonso et al., 2008b).

Oral rehydration, as in parenteral, aims to correct metabolic acidosis, restore blood volume, restore electrolyte balance and provide energy (Rejas et al., 2001). Clinical studies with children and calves have demonstrated that duration of diarrhea is shortened and weight loss is reduced if oral nutrition is maintained (McClure, 2001; Grove-White, 1994). While a few years ago it was recommended not to administer milk to diarrheic calf during the first 48-72 h of therapy with oral rehydration solutions (Alonso et al., 2008a; Rejas and Alonso, 2008), as this would allow the gastrointestinal tract to heal and reduce undigested food in the intestinal lumen, causing osmotic diarrhea (Rainger and Dart, 2006; Rejas and Alonso, 2008).

Currently, it is recommended that the intake of milk (whether natural or milk replacers) be continued at all times; as milk feeding supplemented with oral rehydration solutions, for the treatment of diarrhea, does not cause nor worsen the disease, also these animals that drink milk gain more weight (Rejas and Alonso, 2008; Smith, 2009) and the negative energy balance causes cachexia, which cause harm to the patient by compromising the growth of enterocytes and the immune function (Rejas and Alonso, 2008). Keeping a full diet of milk along with some amount of oral rehydration solutions, greater than or equal to the estimated amount of fluid lost through faeces, is the best choice to manage the diarrhea (Rejas and Alonso, 2008). In Smith (2009) opinion's, calves should be maintained on their full milk diet plus oral electrolytes when possible; if calves are depressed and refuse to suckle, milk can be withheld for one feeding $(12 \mathrm{~h})$ and a hypertonic oral electrolyte product substituted, but the milk feeding should always be resumed within $12 \mathrm{~h}$. In some cases, the problem is the acceptance of oral rehydration solutions for the calf, sometimes even slightly hiporexic. Limiting the amount of milk makes the calf is hungry and more willing to accept oral rehydration solutions (Rejas and Alonso, 2008).
Oral fluids and electrolytes should be administered by the animal sucking them from a teat or by a flexible catheter inserted through the oesophagus (Alonso et al., 2008b). Another possibility, applied in on-farm situations is to administer the solution by a bottle, made of glass or hard plastic, partially inserted in the mouth of the animal and allowing the animal to swallow slowly. This technique must be done carefully because it may cause pneumonia by aspiration. The oral route is absolutely contraindicated in cases of the retention of fluids in the digestive tract (Lisboa, 2004). The oral route is absolutely contraindicated in cases of liquids retention in the digestive tract (Lisboa, 2004).

It is not recommended the administration of more than 2 litres each time, because the distended abomasum and rumen reflux occurs. If you need to give larger amounts they must be given at intervals of $2 \mathrm{~h}$ (Alonso et al., 2008a). It is important to increase the number of administrations to encourage the animal to drink more fluids (Rejas and Alonso, 2008). There is no exact rate for fluid therapy. In general, the maximum amount of oral fluid for a $50 \mathrm{~kg}$ diarrheic calf in a $24 \mathrm{~h}$ period is 8 litres divided into at least 4 feeds of 2 litres or less (Naylor et al., 2006; Rejas and Alonso, 2008). As large amounts of milk may predispose to acidosis, small shots of approximately one litre are recommended (Rejas and Alonso, 2008). Parenteral fluids and oral rehydration solutions should be at body temperature (Rejas et al., 2001).

\section{Parenterally}

There are four routes for parenteral administration: (1) Intravenous, (2) Intraperitoneal, (3) Subcutaneous and (4) Intraosseous (Constable, 2003). The choice of one or the other depends on how hurt the animal is and the practical possibilities for therapy.

\section{Intravenously}

The fluid intravenous therapy is the only permissible way when the degree of dehydration is more than $8 \%$ (Rejas et al., 2001; Alonso et al., 2008b). The parenteral route, especially the intravenous route, with rapid infusion (10 to $20 \mathrm{~mL} \mathrm{~kg}^{-1} \mathrm{BW} / \mathrm{h}$ ) volume replacement is always necessary in cases of severe dehydration and hypovolemic shock. Even moderate dehydration intravenous administration may be necessary in depressed calves without a sucking reflex (Lisboa, 2004). Ideally, the volume replacement can be infused more rapidly than other volumes. In hypovolemic shock forced infusions of $40 \mathrm{~mL} \mathrm{~kg}^{-1}$ body weight/h may be required. If possible, intravenous therapy should be administered for about 6 or $8 \mathrm{~h}$; until the calf is able to stand up, be alert and has a sucking reflex; at this stage you can switch to an oral rehydration (Rejas and Alonso, 2008). The maintenance volume and estimated losses can be infused at a rate of 2 to $5 \mathrm{~mL} \mathrm{~kg}^{-1}$ body weight/h during $24 \mathrm{~h}$ of 
treatment (Lisboa, 2004), i.e., it is divided in 2 to 4 administrations during the day.

\section{Subcutaneous}

Subcutaneous rehydration can be replaced in some cases of orally route. Absorption takes place in the following 4-6 $\mathrm{h}$ after injection, but this requires that the degree of dehydration is less than $8 \%$. If however, dehydration is greater than $8 \%$ reabsorption is much slower as a result of peripheral vasoconstriction (Alonso et al., 2001). This route may be associated with intravenous administration in cases of severe dehydration, especially when potassium is provided (Alonso et al., 2001).

The effectiveness of subcutaneous fluid administration have not been evaluated in experimentally dehydrated neonatal or adult ruminants. Except calcium and magnesium solutions, which are used to treat hypocalcemia and hypomagnesemia, fluids rarely administered subcutaneously in ruminants because absorption rate is suspected to be slow (Constable, 2003). The solutions to be applied should be isotonic solutions of electrolytes and glucose $(5 \%)$ which can be administered up to $80 \mathrm{~mL} \mathrm{~kg}^{-1}$ at different points of application (up to $20 \mathrm{~mL} \mathrm{~kg}$ per application) (Alonso et al., 2008a). Constable (2003) suggests that, to facilitate absorption, can be added hyaluronidase can be added the solution ( $150 \mathrm{U} / \mathrm{L}$ solution), but it has not been given its safety and efficacy.

\section{Intraperitoneally}

The effectiveness of intraperitoneal fluid administrations have not been evaluated in dehydrated neonatal or adult ruminants. Although intraperitoneal fluid has been used in dehydrated calves, this route is not recommended because of the possible alteration of the peritoneal absorption in these types of calves and the risk of peritoneal adhesions. The safe administration of plasma to neonatal calves through a catheter inserted in the paralumbar fossa has been reported (Constable, 2003).

In dehydrated goats, intraperitoneal hydration showed that a higher proportion of water was retained in comparison with central rehydration and this was related to a more effective kidney retention mechanism (lower glomerular filtration rate and higher tubular reabsorption); plus higher proportions of water were retained in the rumen and thirst saturation was more effective (Silanikove, 1991).

\section{Intraosseous}

It is unlikely that the intraosseous route is needed in ruminants, because of their large size and easy accessible veins for catheterization (Constable, 2003). Contrary to what happens in carnivores and birds, there seems to be no reports of intraosseous fluid administration in ruminants (Constable, 2003).

\section{Setting up a Fluid Line}

While most calves can be treated on the farm, it is preferable to hospitalize all those cases requiring intravenous therapy (Grove-White, 1994). Intravenous administration of large volumes of solutions requires intravenous catheterization and periodic monitoring of the flow rate and application devices.

There are many descriptions of the technique for intravenous catheterization (jugular and auricular veins) and for administering fluids. Catheterization is best performed with the calf sedated, in lateral recumbency, with its legs tightly tied up. The jugular vein is located and a small incision $(2.5 \mathrm{~cm})$ is made to expose the vein. A 3 inch and 14 gauge catheter is placed in the vein and sutured in place. It is customary to place a three-way tap and sutured in place at two or three points, ensuring its attachment to the calf. The three-way tap enables blood sampling and an easy administration of other additional drugs (Grove-White, 1994).

It is often difficult to maintain a catheter and a flow rate, as a result of changes in the animal's position (lateral recumbency, standing, rotating the neck, etc.) altering the hydrostatic pressure gradient and because movement can lead to tangling of the fluid line. Even sometimes the animals themselves, especially in young animals, lick and nibble the fluid-administration line, especially when intravenous fluids are administered on farms situations (Constable, 2003). It is advisable to administer a long-acting antibiotic to minimize the risk of thrombophlebitis (Grove-White, 1994).

\section{Solutions for Parenteral Use}

Parenteral fluid therapy: Sterile crystalloid solutions are used. These balanced polyionic solutions, preferably isotonic, i.e., with an osmolality close to the plasma provide electrolytes and even precursors, allowing simultaneous correction of imbalances in water, electrolyte and acid-base (Lisboa, 2004; Rejas et al., 2001).

Commercial products are derived from human line, packaged in bottles of $500 \mathrm{~mL}^{-1}$ and 1000 . The most frequently used are:

- Saline $(0.9 \% \mathrm{NaCl})$ isotonic and provides $\mathrm{Na}^{+}$and $\mathrm{Cl}^{-}$

- Ringer's solution: Isotonic and provides $\mathrm{Na}^{+}, \mathrm{Cl}^{-}, \mathrm{K}^{+}$ and $\mathrm{Ca}^{2+}$

- $\quad$ Ringer lactate solution: Isotonic and provides $\mathrm{Na}^{+}$, $\mathrm{Cl}^{-}, \mathrm{K}^{+}, \mathrm{Ca}^{2+}$ and lactate

- Glucosaline solution ( $5 \%$ glucose and $0.9 \% \mathrm{NaCl})$ : Hypertonic and provides $\mathrm{Na}^{+}$and $\mathrm{Cl}$

These solutions are suitable for the correction of dehydration, hyponatremia, hypochloremia, potassium loss and metabolic alkalosis (Lisboa, 2004).

The correction of metabolic acidosis requires the use of sodium bicarbonate. In the case of ruminants, 
including lactate (base precursor), it has minimal potential alkalizing. The concentration of a lactate Ringer's solution is small and is a racemic mixture, therefore the ability to metabolize D-lactate is negligible. $\mathrm{NaHCO}_{3}{ }^{-}$solution at $1.3 \%$ is ideal and isotonic, but, curiously not marketed. Commercially the following concentrations are: $3,5,7.5,8.4$ and $10 \%$, in $250 \mathrm{~mL}^{-1}$ bottles $10 \mathrm{~mL}$ ampoules to $8.4 \%$ are easily found on the market and can be diluted in $155 \mathrm{~mL}\left(15 \frac{1}{2}\right.$ ampoules) in $845 \mathrm{~mL}^{-1}$ of sterile distilled water to generate a desired $1 \mathrm{~L}$ of isotonic solution (Lisboa, 2004).

The magnitude of metabolic acidosis is variable and does not necessarily correlate with the severity of water imbalance, this is particularly true in cases of ruminal lactic acidosis. The correct assessment of the state of acidosis is obtained only by the blood gas test. Only from the known value of Base Deficit (BD) would it be possible to accurately calculate the amount of $\mathrm{HCO}_{3}{ }^{-}$ suitable for correction, using the following formula: (Lisboa, 2004):

$$
\begin{aligned}
& \mathrm{HCO} 3-\text { deficit }(\mathrm{mEq})=\mathrm{BD}(\mathrm{mEq} / \mathrm{L}) \times \mathrm{BW}(\mathrm{kg}) \\
& x 0.51 \mathrm{~g} \text { of } \mathrm{NaHCO}_{3} \text { equals } 12 \mathrm{mEqHCO}_{3}^{-}
\end{aligned}
$$

Unable to perform a blood gas analysis, which is common for a veterinarian who operates on the farm, one can estimate the degree of acidosis based on subjective criteria; i.e., based on the severity of depression, assuming a margin of error. A value of 10 $\mathrm{mEq} / \mathrm{L}$ estimated could be accepted as reasonable for diarrheal calves with moderate to severe dehydration, as well as for cattle with ruminal lactic acidosis depressed, but still standing (Lisboa, 2004).

Intravenous fluids are usually given through a catheter in the jugular vein or auricular (ear). Catheterization of the auricular vein in calves described in detail previously (Smith and Berchtold, 2014).

\section{Solutions for Oral Use}

For practical reasons and especially under on-farm conditions, prolonged intravenous infusions are rarely performed in ruminants; because of the need for monitoring and complications with maintaining the integrity of the infusion system (catheters, equipment, extenders and bottles). These limiting factors have served as a great stimulus for oral hydration. In fact, oral hydration with appropriate solutions can be considered, at present, the option of choice for the treatment of diarrheic calves due to their effectiveness, convenience and low cost (Rejas et al., 2001; Lisboa, 2004; Sen et al., 2009; Smith, 2009).

Multiple products have been reported for use orally in veterinary medicine, mainly oriented towards the treatment of diarrheal calves (Alonso et al., 2001; Lisboa, 2004; Sen et al., 2009; Smith, 2009; Meganck et al., 2014).
The solutions aim is to promote correct dehydration, hyponatremia, hypochloremia, potassium loss and metabolic acidosis. Its ionic composition obeys the principle of maximum efficiency in the absorption of sodium and therefore water by the enterocytes. The presence of glucose and glycine increase this efficiency, due to the existence of absorption mechanisms as cotransport of $\mathrm{Na}^{+} /$glucose and $\mathrm{Na}^{+} /$amino acids (Constable et al., 2001; McClure, 2001). Osmolarity close to that of plasma or slightly above, also contributes to increased efficiency of absorption (Lisboa, 2004).

The ingredients used to prepare these solutions must be cheap and easy to acquire $\left(\mathrm{NaCl}, \mathrm{KCl}, \mathrm{NaHCO}_{3}\right.$ or sodium citrate and dextrose); and they can be stored as a powder in packets ready to be diluted in water (Lisboa, 2004).

The World Health Organization (WHO) has recommended, since the $70 \mathrm{~s}$, a rehydration solution with the following ionic composition: $90 \mathrm{mmol} \mathrm{L}^{-1}$ of $\mathrm{Na}, 80$ mmol L ${ }^{-1} \mathrm{Cl}, 20 \mathrm{mmol} \mathrm{L}^{-1}$ of $\mathrm{K}, 30 \mathrm{mmol} \mathrm{L}^{-1}$ of $\mathrm{HCO}_{3}^{-}$ and $100 \mathrm{mmol} \mathrm{L}^{-1}$ of dextrose, with osmolarity of 320 mOsm L ${ }^{-1}$ (Lisboa, 2004). Later, in 1986, WHO has replaced $\mathrm{HCO}_{3}{ }^{-}$for citrate (base precursor) to increase their shelf life.

Another solution that has been used with satisfactory results in calves is composed of $2.5 \mathrm{~g}$ of $\mathrm{NaCl}, 1.5 \mathrm{~g} \mathrm{KCl}$, $5 \mathrm{~g} \mathrm{NaHCO}_{3}$ and $28 \mathrm{~g}$ dextrose diluted in 1 litre of water. The preparation is simple. The $\mathrm{NaHCO}_{3}$ may be replaced by $5 \mathrm{~g}$ of sodium acetate. The final osmolarity is 390 mOsm L $\mathrm{L}^{-1}$ ) (Lisboa, 2004). In adult ruminants the following solution has been recommended: $160 \mathrm{~g} \mathrm{NaCl}$, $20 \mathrm{~g} \mathrm{KCl}, 10 \mathrm{~g}$ of $\mathrm{CaCl}_{2}$ and $300 \mathrm{~mL}^{-1}$ of propylene glycol diluted in $20 \mathrm{~L}$ of water. It should be noted that this solution does not allow the correction of acidosis, since both bicarbonate as base precursors are metabolized in the rumen microbial fermentation process (Lisboa, 2004).

Glucose (or lactose) in oral fluid mixtures is present only to aid in sodium and water absorption, it is a totally inadequate energy source for calves (Constable et al., 2001; McClure, 2001; Grove-White, 1994).

\section{Rate of Fluid Administration}

There is no exact rule for administration of fluid therapy. The key to deciding the rate at which to administer fluids must be the response to treatment, this is the best guide to assess the required amount of liquid (Grove-White, 1994). Although clinical signs, such as the sinking of the eye and skin tenting, are indicative that a calf is dehydrated, they can be notoriously inaccurate concerning the measurement of hematocrit and plasma proteins (Grove-White, 1994). The use of portable analyzers can be of great value to evaluate the acid-base changes during therapy and can also help decisions to be made regarding the composition of intravenous fluid used and the quantity, particularly in the severely acidotic but minimally dehydrated calves in which there 
are no clear signs other than weakness and collapse (Grove-White, 1994).

At this point we should distinguish two types of situations: 1. Hospitalized animals, in which fluid may be infused intravenously for many h; and 2 . Individuals in the stable, in which the intravenous fluid has to be administered quickly (Rejas and Alonso, 2008).

The recommended rate, particularly IV infusion, is from 20 to $40 \mathrm{~mL} \mathrm{~kg}^{-1} \mathrm{~h}$. The usual aim is to correct dehydration in about 6 to $8 \mathrm{~h}$ and then gradually administer the remaining fluids required for maintenance and ongoing losses (Naylor et al., 2006).

Usually half the estimated fluids and electrolyte deficits must be corrected in the first $6 \mathrm{~h}$ and the remainder for the next $18 \mathrm{~h}$ in order to complete $24 \mathrm{~h}$. However it is possible and often beneficial, to proceed more rapidly (Grove-White, 1994); and an initial speed fluid delivery of up to $80 \mathrm{ml} \mathrm{kg}{ }^{-1} \mathrm{~h}$ can be used safely, administering up to 2 litres during the first $30 \mathrm{~min}$ of therapy and the remainder more slowly over the subsequent 24 to $48 \mathrm{~h}$. A shocked calf with severe dehydration may need between 5 to 20 litres of liquid over 24 to $48 \mathrm{~h}$ (Grove-White, 1994).

Alternatively, during the first day and in hospitalized animals, the fluid therapy is divided into 3 periods. During the first three $h$ half the existing losses should be administered (half the degree of dehydration) and correct at least half of the existing acidosis. Thus, in less than three $\mathrm{h}$, the calf will have a mild dehydration and mild acidosis. During the next $5 \mathrm{~h}$, until $8 \mathrm{~h}$, the rest of lost fluids (rest of the degree of dehydration) were administered, correcting the rest of acidosis, although a mild acidosis can be corrected by renal function if you have liquids and electrolytes. At this point it is convenient to start managing solutions to replace potassium losses, once the hyperkalemia secondary to acidosis has been corrected. According to the patient, this rehydration can be intravenously or orally with oral rehydration solution. Between 8 and $24 \mathrm{~h}$, daily maintenance needs $\left(50-70 \mathrm{~mL}^{-1} \mathrm{~kg}^{-1}\right)$ and estimated future losses (1-4 L) are administered, usually orally (Rejas and Alonso, 2008).

Often slower infusion rates ( 30 to $50 \mathrm{~mL} \mathrm{~kg}^{-1} \mathrm{~h}$ ) are used to prevent overhydration and pulmonary edema. Therefore at a speed of 30 to $40 \mathrm{~mL} \mathrm{~kg}^{-1} \mathrm{~h}$, a calf of 40 $\mathrm{kg}$ with $10 \%$ dehydration can be rehydrated in less than 3 to $4 \mathrm{~h}$ and also the volumes of liquids daily maintenance ( 80 to $100 \mathrm{~mL} \mathrm{~kg}^{-1}$ ) and continuing losses of up to 7 litres per day need to be added in order to calculate daily fluid necessities. Rates of $30 \mathrm{~mL} \mathrm{~kg}^{-1}$ for a number of $\mathrm{h}$ produce no toxic side effects (Bjorling and Rawlings, 1983; Broaddus et al., 1990; Gottardo et al., 2002). However, if the calf can suck after initial resuscitation the required fluids can be administered orally to reduce costs and labour (Smith and Berchtold, 2014).
It has been found that a high rate of infusion fluid for intravenous administration of $80 \mathrm{ml} \mathrm{kg}^{-1} \mathrm{~h}$ does not cause significant hypertension over hydration. This rate is equivalent to a maximum volume of liquid of $2.8 \mathrm{~L}^{-1} \mathrm{~h}$ for a $35 \mathrm{~kg}$ calf or $3.8 \mathrm{~L}^{-1} \mathrm{~h}$ for a $47 \mathrm{~kg}$ calf, severely dehydrated. No higher rhythms are recommended (Smith and Berchtold, 2014), since studies in sheep and healthy cats indicate that fluid overload occurs at delivery rates of about $90 \mathrm{~mL} \mathrm{~kg}^{-1}$ for periods longer than one h (Naylor et al., 2006). Some sick calves with hypoproteinemia or increased vascular permeability are likely to be more susceptible to volume overload (Naylor et al., 2006).

In practice, very rapid rates of intravenous fluid infusion, $100 \mathrm{~mL} \mathrm{~kg}^{-1} \mathrm{~h}$ can be used for short periods of time (no more than $20 \mathrm{~min}$ ) in the initial resuscitation of calves with severe dehydration. The aim of this high initial rate of infusion is to rapidly improve circulation by restoring blood volume (Naylor et al., 2006). Based on plasma volume of $7.2 \%$ of body weight fluid administration at this speed will increase plasma volume by almost 50\% (Naylor et al., 2006).

\section{Prognosis and Therapy Duration}

As previously stated, clinical signs such as the ability to stand up, the intensity of suction, the loss of the blinking reflex and the age of diarrheal calves are essential to determine whether the treatment with fluids is functioning properly. Urination in 30 to 60 min after therapy, improved mental state and hydration and the most important, restoration of the sucking reflex should be supervised in treatment responses (Smith and Berchtold, 2014).

Decubitus calves must stand up for a few $\mathrm{h}$ after fluid therapy. If the sucking reflex does not return after IV therapy, other diseases such as septicemia, omphalitis, or pneumonia should be ruled out (Smith and Berchtold, 2014) and it would be advisable to check the acid-base status of the animal, especially in calves (adding bicarbonate and even potassium). It is necessary to note that determining a possible acidosis in the farm is difficult and costly and the administration of alkalizing is done without any laboratory data, which influences the clinical response to fluid therapy (Smith and Berchtold, 2014).

The length of hospitalization varies, but generally speaking the calves are discharged after 48 to $72 \mathrm{~h}$, at which time they will be able to suckle and drink fluids orally. As in all diseases of calves, the immune status of the calf is of great importance in relation to the prognosis (Grove-White, 1994). As a rule, those calves with a very low immunoglobulin level die despite treatment (Grove-White, 1994).

The prognosis for calves with longstanding diarrhea is also poor, in part because they will have a very serious negative energy balance despite the fact 
that they may be receiving oral fluids containing glucose (Meganck et al., 2014).

\section{Source of Fluids Fluid Composition}

Although there are many preparations that can be used in fluid therapy to be found on the market either oral or parenteral, only a few are used in routine practice. The fluids are categorized on the basis of their physical nature (crystalloid or colloid) and osmolarity (hypoosmotic, iso-osmotic, or hyperosmotic) (Table 4). Isosmotic or slightly hypo-osmotic crystalloid solutions most commonly are administered parenterally, although under specific circumstances hyperosmotic crystalloid solutions or iso-osmotic colloid solutions are preferred (Constable, 2003).

A crystalloid is a substance that forms a true solution and is capable of being crystallized. $\mathrm{NaCl}$ is the classic crystalloid because there as a crystal and also dissolves completely when is placed in water. As crystalloid solutions on the market are Ringer's solution, lactated Ringer's solution, acetated Ringer's solution, $0.9 \%$ sodium chloride $(\mathrm{NaCl}), 7.2 \% \mathrm{NaCl}$ (hypertonic saline), $1.3 \%$ sodium bicarbonate $\left(\mathrm{NaHCO}_{3}\right), 8 \% \quad \mathrm{NaHCO}_{3}$, calcium gluconate and 50\% dextrose (Constable, 2003). Solutions crystalloid and especially those containing sodium, are indicated in hypovolemia, but are contraindicated in congestive heart failure and in animals with severe hypoalbuminemia (Constable, 2003), because sodium retention can aggravate heart disease and because sodium decreased plasma albumin; and therefore oncotic pressure, resulting in movement of fluid into the interstitial spaces and exacerbating tissue oedema (Constable, 2003).

A colloid is a substance that is too large to pass through a semi permeable membrane. Examples of colloid solutions administered to ruminants are whole blood, plasma, dextrans, hydroxyethyl starches and gelatins (Constable, 2003). Intravenous colloid therapy is based on the premise that the large molecular size of colloids ensures their retention within the intravascular space. Consequently, intravascular volume expansion is greater and of longer duration when colloids, rather than crystalloids are infused (Hughes, 2001). Colloid solutions are excellent for sustained expansion of plasma volume, while are contraindicated in congestive heart failure and in the presence of oliguric or anuric renal failure (Constable, 2003). Colloids represent a therapeutic modality with specific indications, contraindications, benefits and risks. In comparison, balanced electrolyte solutions are relatively safe, inexpensive and physiological. The high cost of some colloidal solutions restrains the use versus crystalloid fluid administration in many clinical situations (Hughes, 2001).

To understand some aspects of the fluids used in fluid therapy two terms must be understood: osmolality and osmolarity. Osmolality is the number of dissolved particles per kilogram of solution and is expressed as $\mathrm{mOsm} / \mathrm{kg}$ of solution. Osmolarity expresses the level of concentration of various solutions components, defined as the number of particles per litre of solution and is expressed as $\mathrm{mOsm} / \mathrm{L}$ of solution. The correct term in plasma and extracellular fluid is osmolarity, since osmoles are dissolved in water only and not throughout the volume of the solution; it has a certain volume occupied by the solutes. However, we know that usually the difference between one and another way of expressing and preparing a solution is minimal; and therefore can $\mathrm{mOsm} / \mathrm{kg}$ or $\mathrm{mOsm} / \mathrm{L}$ can be used interchangeably, but in other cases the difference is large and it is recommended to use $\mathrm{mOsm} / \mathrm{kg}$. One $\mathrm{kg}$ of plasma approaches $1 \mathrm{~L}$ plasma; therefore osmolarity can be easily calculated from the concentration of electrolytes in the fluid solution. Onekg $(1 \mathrm{~L})$ of plasma has two components, $70 \mathrm{~g}$ protein and $930 \mathrm{~g}$ of water and plasma. Accordingly, normal plasma osmolality in ruminants is approximately $285 \mathrm{mOsm} \mathrm{kg}^{-1}$ and may increase by drinking water (osmolality $>285 \mathrm{mOsm} \mathrm{kg}^{-1}$ ) or by increasing the excretion of free water (osmolality $<285 \mathrm{mOsm} \mathrm{kg} \mathrm{kg}^{-1}$ ). An osmolality of $285 \mathrm{mOsm} \mathrm{kg} \mathrm{m}^{-1}$ is equivalent to a plasma water osmolarity of $306 \mathrm{mOsm}$ $\mathrm{L}^{-1}$ ([285 mOsm/kg]/[0.93 $\left.\mathrm{L} \mathrm{kg}^{-1}\right]$ ) (Constable, 2003).

The normal plasma osmolality for ruminants is 306 mOsm $\mathrm{L}^{-1}$, therefore we can define the solutions used in fluid therapy as iso-osmolar (300 to $312 \mathrm{mOsm} \mathrm{L}^{-1}$ ), hyperosmolar ( $>312 \mathrm{mOsm} \mathrm{L}^{-1}$ ) and hypo-osmolar $\left(<300 \mathrm{mOsm} \mathrm{L}^{-1}\right)$ (Constable, 2003, 561). Using this classification, it is clear that some routinely used crystalloid solutions are hypo-osmotic; in particular, lactated Ringer's solution ( $\left.275 \mathrm{mOsm} \mathrm{L}^{-1}\right)$ is slightly hypo-osmotic and $5 \%$ dextrose $\left(250 \mathrm{mOsm} \mathrm{L}^{-1}\right)$ is moderately hypo-osmotic, although after glucose metabolism, 5\% dextrose becomes a markedly hypoosmotic solution (Constable, 2003). Ringer's solution, $0.9 \% \mathrm{NaCl}$ and $1.3 \% \mathrm{NaHCO}_{3}$ therefore are considered iso-osmotic solutions because they distribute in plasma water and an osmolarity of 309,308 and $310 \mathrm{mOsm} \mathrm{L}^{-1}$, has been calculated, respectively, (Constable, 2003). Because of hemolysis induced hypo-osmolarity fluids parenterally administered fluids should be iso-osmotic or hyperosmotic (Constable, 2003).

\section{9\% Sodium Chloride Solution}

Isotonic saline, also called physiological saline, is an iso-osmotic solution that little used in the routine therapy of sick ruminants because ruminants often develop hypocalcemia and hypokalemia when suffering from lack of appetite. The $0.9 \% \mathrm{NaCl}$ is used in cleansing wounds, in surgical procedures and as a vehicle for other electrolytes and dextrose. It is a slightly acidifying solution (Constable, 2003). 


\section{Ringer's Solution}

Ringer's solution is a balanced, polyionic, non alkalizing, iso-osmotic, crystalloid solution containing physiological concentrations of $\mathrm{Na}^{+}, \mathrm{K}^{+}, \mathrm{Ca}^{2+}$ and $\mathrm{Cl}^{-}$. Ringer's solution is the standard intravenous fluid for adult ruminants because these animals tend to become alkalemic when they suffer from lack of appetite (Constable, 2003). Like the $0.9 \% \mathrm{NaCl}$ solution is slightly acidifying solution (Constable, 2003).

\section{Lactated Ringer's Solution}

Ringer's lactate (frequently abbreviated as LRS), is

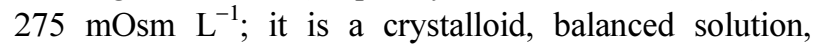
polyionic, alkalizing, iso-osmotic containing physiological concentrations of $\mathrm{Na}^{+}, \mathrm{K}^{+}, \mathrm{Ca}^{2+}, \mathrm{Cl}^{-}$and lactate.

It is used to correct dehydration and mild electrolyte imbalance in ruminants, because the lactate is predominantly metabolized to bicarbonate ion, which can increase blood $\mathrm{pH}$. Because accurate lactate metabolism to produce the alkalizing effect, it is considered to have weak alkalizing or slow capacity and it is not recommended for ruminants with severe acidemia (Constable, 2003; Smith and Berchtold, 2014).

A possible disadvantage of the commercially available LRSis that lactate is an equimolar racemic mixture of L-lactate and D-lactate, so its use should be avoided in severely acidemic calves, since it can increase the concentrations of D-lactate (Constable, 2003; Smith and Berchtold, 2014). In healthy animals the L-lactate is rapidly metabolized, while ruminant tissues have negligible activity D-lactate dehydrogenase, whereby the excretion of D-lactate is done primarily through the urine (Constable, 2003). Therefore solutions of DL-lactate (as found in lactated Ringers solution) in ruminants have about half of the alkalizing ability than in solutions of Llactate only (Constable, 2003; Smith and Berchtold, 2014). Lactate Ringer's solution is used routinely, in some cases by custom, although in patients, neonatal and adult ruminants, concentrations may be increased in blood lactate; so it would be counterproductive to add lactate to these animals.

\section{Acetated Ringer's Solution}

Acetated Ringer's solution is similar to the RLS; but it contains acetate instead of containing lactate. It is a balanced crystalloid, polyionic, alkalizing, hypoosmotic solution, with $294 \mathrm{mOsm} \mathrm{L}^{-1}$. Commercially available formulations of this solution containing physiological concentrations of $\mathrm{Na}^{+}, \mathrm{K}^{+}, \mathrm{Mg}^{2+}, \mathrm{Cl}^{-}$acetate $\left(\mathrm{CH}_{3} \mathrm{COO}\right)$ and gluconate $\left(\mathrm{CH}_{2}(\mathrm{OH})\{\mathrm{CH}(\mathrm{OH})\}_{4} \mathrm{COO}\right)$ (Constable, 2003; Sen et al., 2009; Smith and Berchtold, 2014).

It is also considered a weak or slow alkalizing fluid and must manage large quantities must be administered to correct dehydration in calves with diarrhea. This acetated Ringer's solution, is theoretically better than the
RLS, since acetate is metabolized more rapidly, therefore alkalinization is faster.

In addition, acetate exacerbates not D-lactic acidosis, present in most calves with diarrhea (Constable, 2003; Smith and Berchtold, 2014). Commercial formulations of acetated Ringer's solution containing gluconate; which like the D-lactate it is metabolized poorly by calves (and possibly also by adults ruminant) (Constable, 2003; Smith and Berchtold, 2014).

\section{Iso-Osmotic Sodium Bicarbonate (1.3\% $\mathrm{NaHCO}_{3}$ Solution)}

Iso-osmotic sodium bicarbonate solution $(1.3 \%$ $\mathrm{NaHCO}_{3}$ ) is an alkalinizing iso-osmotic crystalloid solution, considered a strong alkalizing fluid, that is used to treat severe acidemia (indicated whenever blood $\mathrm{pH}<$ 7.20 due to metabolic acidosis).

Sodium bicarbonate has proved more effective than other bicarbonate precursors (such as lactate or acetate) or other synthetic bases (Smith and Berchtold, 2014), because bicarbonate does not have to be metabolized by the liver to exercise alkalizing effect in the blood (Constable, 2003; Smith and Berchtold, 2014). This solution is alkalizing, since bicarbonate is combined and eliminates $\mathrm{H}^{+}$ions producing $\mathrm{CO}_{2}$ and water.

Isotonic sodium bicarbonate solution $(1.3 \%)$ can be easily prepared by adding sodium bicarbonate $\left(\mathrm{NaHCO}_{3}\right)$ in sterile water (or distilled) at $13 \mathrm{~g}$ per litre $(155 \mathrm{mEq} / \mathrm{L}$ $\mathrm{HCO}_{3}{ }^{-}$) (Constable, 2003). The amount of isotonic bicarbonate necessary to correct acidemia is calculated based on total concentration of $\mathrm{CO}_{2}$ in blood, or the bicarbonate concentration, the value of excess base; and generally ranges between 2 and $5 \mathrm{~L}$, based on the weight of the calf and the severity of acidosis. Although there are rules to calculate bicarbonate needs (Smith and Berchtold, 2014), a simple estimate is to administer isotonic sodium bicarbonate solution for approximately $10 \%$ of the body weight over a period of several $\mathrm{h}$ (for example $4 \mathrm{~L}$ for a calf of $40 \mathrm{~kg}$ ) (Constable, 2003; Smith and Berchtold, 2014).

Bicarbonate should not be used for the treatment of severe respiratory acidosis, because the additional carbon dioxide $\left(\mathrm{CO}_{2}\right)$ generated may worsen respiratory acidosis (Constable, 2003).

\section{2\% Sodium Chloride (Hypertonic Saline)}

This hypertonic saline solution $\left(2460 \mathrm{mOsm} \mathrm{L}^{-1}\right)$ is recommended for rapid expansion of plasma volume of severely dehydrated ruminants and its combination with oral electrolyte solutions or large volumes of LRS. Therefore it can be very effective in resuscitating severely dehydrated calves, being less expensive and easier to administer (Smith and Berchtold, 2014). It is recommended to administer this hypertonic saline at 4 to $5 \mathrm{~mL} \mathrm{~kg}^{-1}$ intravenously for 4 to $5 \mathrm{~min}\left(1 \mathrm{~mL} \mathrm{~kg}^{-1} \mathrm{~min}\right)$ (Constable, 2003; Smith and Berchtold, 2014). Faster administration can cause hemodynamic collapse due to 
vasodilation and decreased cardiac contractility, while slower administration does not provide significant advantages compared to crystalloid solutions iso-osmotic (Constable, 2003). As with large volumes $\mathrm{NaCl} 0.9 \%$ small amounts of hypertonic saline consistently induce mild acidosis (Constable, 2003), although the decrease in $\mathrm{pH}$ after administration of hypertonic saline is less than 0.08 units and disappears rapidly with time. Therefore, the effect of hypertonic saline in the acid-base balance is clinically inconsequential (Constable, 2003).

Hypertonic saline is also indicated for the treatment of hyperkalemia in calves (Smith and Berthold, 2014).

\section{4\% Sodium Bicarbonate}

The Hypertonic Sodium Bicarbonate (HSB), commercially available as $8.4 \%$ solution, contains sodium bicarbonate $1 \mathrm{mEq} \mathrm{mL} \mathrm{m}^{-1}$ and a total osmolarity of 2000 mOsm L ${ }^{-1}$ (Smith and Berchtold, 2014; Constable, 2003, 564). It's used for the correction of severe acidosis and dehydration in ruminants, especially calves with diarrhea (Walker et al., 1998; Constable, 2003; Smith and Berchtold, 2014).

It's recommended for rapid alkalization in presence of severe acidemia $(\mathrm{pH}<7.2)$, providing $1 \mathrm{mEqHCO}_{3}{ }^{-}$ per $\mathrm{ml}$ of solution, which facilitates the calculation of the volume to be administered.

The rate of intravenous administration of $8.4 \%$ $\mathrm{NaHCO}_{3}$ should not exceed $1 \mathrm{ml} \mathrm{kg}^{-1}$ min (Constable, 2003). Theoretically, the product must generate an osmotic movement of water and electrolytes from the gastrointestinal tract into extracellular space, similar to a hypertonic saline (Smith and Berchtold, 2014). However the HSB should not be used in diarrheic calves that have concurrent respiratory diseases; as these calves may not be able to effectively exhale excess $\mathrm{CO}_{2}$ generated (Smith and Berchtold, 2014).

\section{5\% Dextrose}

This solution, abbreviated D5W, has $250 \mathrm{mOsm} \mathrm{L}^{-1}$, but plasma osmolality decreases as glucose is metabolized, leaving the water free (Constable, 2003, 564). It is the only non-alkalizing fluid that is generally used in neonatal ruminants. Dextrose is often added to other solutions, from 5 to $10 \%$ to offset the negative energy balance in diarrheic calves, whether or not showing hypoglycemia (Smith and Berchtold, 2014). Because $5 \%$ dextrose solution has no sodium to expand the extracellular volume, its only application in ruminants is to provide free water (Constable, 2003; Smith and Berchtold, 2014).

In practice to provide energy and rehydrate the newborn, add 25 to $50 \mathrm{~g}$ of dextrose or 50 to $100 \mathrm{~mL}^{-1}$ of a solution of $50 \%$ dextrose to 1 litre of LRS or isotonic sodium bicarbonate to make a slightly hypertonic solution (Smith and Berchtold, 2014).

\section{D-Lactic Acidosis in Ruminants}

Diarrhea, ruminal acidosis (in so-called ruminal drinkers) and acidosis without dehydration syndrome are the main causes of morbidity and mortality in new-born calves. For years we have known that adult ruminants, with acute ruminal acidosis, D-lactic acidosis develop after rumen overload and that increasing concentrations of D-lactate are responsible for most of the systemic acidemia, which occurs in calves called "syndrome acidosis-without-dehydration" and in cases of diarrhea in calves with a significant dehydration (Berchtold, 2009). The importance of lactate and especially the isomer Dlactate in the path physiology of various gastrointestinal diseases in ruminants has expanded in recent years with several clinical and experimental studies. Therefore, we think it is appropriate to review some aspects of the importance of D-lactic acid for the development of clinical signs and therapy for the treatment of these syndromes (Gentile et al., 2004; Lorenz et al., 2005; Naylor et al., 2006; Gentile et al., 2008).

As indicated above the objectives of fluid therapy in ruminants, especially in calves with gastrointestinal disease, they are to correct dehydration, to correct the acidemia; and the special aspect of reducing D-lactate concentrations. We should take this value as less than 1 mmol L ${ }^{-1}$ (Naylor et al., 2006).

It is known that in calves with enteritis and diarrhea, dehydration is a contributing factor to the CNS depression. However, this alone would not be able to produce the profound depression which is observed in some diarrheic calves (Walker et al., 1998; Constable, 2003). Given the ability of D-lactate to produce profound weakness, ataxia and CNS depression and considering that there is an increase of D-lactate in calves with severe diarrhea, it seems likely that the Dlactate is partly responsible for these clinical signs (Walker et al., 1998; Meganck et al., 2014).

As indicated elsewhere in this article the ruminants, especially calves more than a week old, show a high production of lactic acid. Both isomers, D- and L-lactate, are produced in the gastrointestinal tract of ruminants by bacterial metabolism of carbohydrates without any harmful consequence for the animal (Berchtold, 2009). In adult cattle the fermentation of large amounts of carbohydrates induces an increase in the concentration of organic acids which leads to a decrease in $\mathrm{pH}$ intraruminal, which favours the overgrowth of certain bacteria (which are capable of producing large quantities of D- and L-lactate (Dirksen et al., 2005; Berchtold, 2009; Smith, 2009). A similar effect occurs in calves with diarrhea; increased production of D- and L-lactate, probably due to villus atrophy, malabsorption of nutrients and increased intestinal fermentation by bacteria present in the intestine (Berchtold, 2009). Both isomers (D- and L- lactate) are absorbed through the blood (Berchtold, 2009). 
In healthy animals L-lactate is rapidly metabolized, while ruminant tissues have negligible activity D-lactate dehydrogenase, whereby the removal of D-lactate is done primarily through excretion in the urine (Constable, 2003; Berchtold, 2009; Meganck et al., 2014). Therefore, metabolic acidosis that develops is mainly caused by increasing concentrations of D-lactate (Naylor et al., 2006; Berchtold, 2009). Since the D-lactate also only be removed efficiently by the kidneys, dehydration may have an indirect role in the increased toxicity of D-lactate (Ewaschuk et al., 2004; Naylor et al., 2006).

\section{Relative Contribution of Dehydration, Acidemia and D-Lactic Acid to Clinical Signs in Gastrointestinal Disease}

Calves with gastrointestinal disorders may show signs of neurological dysfunction, including ataxia, weakness and reduced food intake. These systemic signs are collectively referred to as malaise and may be the result of dehydration, acidosis, endotoxemia or sepsis. Therefore the accumulation of D-lactate in blood seems to be one of the most important factors in the pathogenesis of systemic signs of weakness and CNS depression in calves with gastrointestinal disease; playing a major role in the development of malaise in sick calves and even in its death (Kasari and Naylor, 1986; Lorenz et al., 2005; Naylor et al., 2006; Trefz et al., 2012a; Meganck et al., 2014).

No obvious correlation between the serum levels of D-lactate and dehydration. Variations in behaviour, posture and palpebral reflex are more closely correlated with elevations of saerum D-lactate concentrations than with decreases in base excess. However, impairment of a good sucking reflex is more related to the degree of dehydration than it reflects acidosis (Meganck et al., 2014).

There are even researches showing that the D-lactate produced these clinical signs when it is administered experimentally at calves (Lorenz et al. 2005; Naylor et al., 2006). In general, this suggests that the D-lactate is responsible for most of the clinical signs in calves with acidosis and without dehydration syndromes. The Dlactate easily penetrates the space of Cerebrospinal Fluid (CSF) -with concentrations similar to serum- and it is thought than the loss of fighting reflex threat, the blinking reflex, the panicular reflex and the ability to stand are highly correlated with the concentration Dlactate in the CSF (Naylor et al., 2006; Berchtold, 2009). Interestingly, losses of the reflex of suckle correlates poorly with the concentration of D-lactate and, unlike other reflexes, correlates well with the degree of acidemia. (Gentile et al., 2004; 2008; Lorenz et al., 2005; Naylor et al., 2006; Lorenz, 2009; Trefz et al., 2012b; Meganck et al., 2014). The role of acidemia is less clear and several experiments documented that the correction of acidosis or preventing acidemia, enhance survival of diarrheic calves (Booth and Naylor, 1987; Naylor et al., 2006). Although the mechanism is unclear, it is possible that the correction of academia simply accelerates the removal of D-lactate from the body (Naylor et al., 2006).

CSF $\mathrm{pH}$ falls more slowly than blood $\mathrm{pH}$ and some time is required before the effects of acidemia (Naylor et al., 2006) are fully noticed. Acidemia also affects the intracellular and extracellular potassium concentrations and acidosis favors the movement of potassium from the cells into serum. These alterations in potassium levels predispose to the development of cardiac arrhythmias and cause weakness or even death (Naylor et al., 2006).

In ruminal acidosis in adult cattle is likely that the relative contributions of dehydration, acidemia and Dlactate are similar to those of diarrheic calves (Naylor et al., 2006).

\section{Correction of Acidosis in Ruminants}

We know that the simple fluid replacement without alkalizing is not effective in the treatment of diarrhea in calves. Therefore, to achieve the correction of acidosis, sodium bicarbonate is the treatment of choice for its immediate action on acid-base balance (Alonso et al., 2001; 2008b). Sodium bicarbonate is an effective alkalizing agent; a fact that has been empirically demonstrated in blind, randomized, controlled studies in diarrheic calves and calves with acidosis and dehydration syndrome (Kasari and Naylor, 1986; Booth and Naylor, 1987; Naylor et al., 2006; Smith, 2009; Trefz et al., 2012a).

Bicarbonate can be given IV as an isotonic or hypertonic solution. In the field it is more practical to use a hypertonic compared with an isotonic solution. Rapid IV administration of an $8.4 \%$ bicarbonate formulation at $5-10 \mathrm{~mL} \mathrm{~kg}^{-1}$ provided an effective and safe method to improve acid-base abnormalities (Meganck et al., 2014).

The infusion of bicarbonate must be done with caution, since overdosing intravenously may cause a rise in $\mathrm{PCO}_{2}$ which translates clinically hyperventilation (to remove the $\mathrm{CO}_{2}$ produced), an excess of $\mathrm{Na}^{+}$ (hypernatremia) which causes hyperosmolarity and extracellular alkalosis $\left(\mathrm{HCO}_{3}{ }^{-}\right.$excess ions) accompanied by cardiac arrhythmia and increased tissue needs oxygen causing a secondary hyperlactatemia.

The base deficit is the most useful parameter to quantify metabolic acidosis and it allows to quantify the therapeutic requirements of bicarbonate in sick calves. In this case, the amount of sodium required to correct metabolic acidosis is given by the formula: (Naylor et al., 2006; Meganck et al., 2014). 


\section{Sodium Bicarbonate Requirement, $\mathrm{mmol}=$ Body weight, $K g x$ Base Deficit $x$ Vd}

Where $\mathrm{Vd}$ is the volume of distribution of bicarbonate and has been experimentally determined in healthy calves, in calves with diarrhea and calves with acidosis without dehydration syndrome (Kasari and Naylor, 1986).

Although in practice; a value of $\mathrm{Vd}=0.5$ is used, it may range from 0.45 to 0.75 , depending on the plasma proteins and phosphate buffering systems between calves and on differences in the degree of intracellular acidosis (Naylor et al., 2006; Meganck et al., 2014).

If a serum bicarbonate is available, bicarbonate requirements can be calculated from the bicarbonatemia, using the following formula with a $\mathrm{Vd}$ of 0.6 (to compensate for buffering by non-bicarbonate systems) (Suzuki et al., 2002; Naylor et al., 2006).

\section{Sodium Bicarbonate Requirement, $\mathrm{mmol}=$ Body Weight, kg x (30-Patient Bicarbonate) $x$ Vd}

Normally the correction of acidosis requires 1 to $4 \mathrm{~L}$ ( 25 to $100 \mathrm{~mL} \mathrm{~kg}^{-1}$ ) of an isotonic solution of sodium bicarbonate $(1.3 \%)$, administered intravenously over about 4 to $8 \mathrm{~h}$ (Suzuki et al., 2002; Naylor et al., 2006). It is possible that this rapid correction produces a paradoxical CSF acidosis. In severely acidotic calves treated with sodium bicarbonate, a residual depression may appear that requires 12 to $18 \mathrm{~h}$ to resolve. This may be due to the correction of acidosis in the CSF, the clearance of Dlactate or some other factor (Naylor et al., 2006).

Hypertonic solutions of sodium bicarbonate (8.4\%) have been tested in new-born calves, with experimentally induced respiratory acidosis at doses of $5 \mathrm{~mL} \mathrm{~kg}^{-1}$ for 5 min, with satisfactory results (Naylor et al., 2006; Berchtold, 2009). Although some diarrheic calves show normonatremia, others are hyponatremic and others are severely hypernatremic, therefore hypertonic sodium bicarbonate should be used cautiously in calves unless the serum sodium concentration has been measured (Naylor et al., 2006).

Oral acidemia correction can be achieved with electrolyte solutions containing bicarbonate, acetate, citrate or other metabolizable bases. Bicarbonate, administered orally, is not directly effective, it is first neutralized by the acidity of the abomasum. Systemic alkalinization occurs when pumps protons abomasal regenerate abomasal acid, with an equal addition of bicarbonate to the systemic circulation. Since oral electrolyte therapy is only recommended for calves not severely compromised, the metabolism of bases such as acetate is unlikely to deteriorate. In a trial with an oral electrolyte solution containing acetate, it was slightly more effective than an identical solution containing bicarbonate in correcting acidemia. Generally, bicarbonate is avoided in oral electrolyte solutions due to concerns that it increases the $\mathrm{pH}$ of the abomasum and thereby facilitates the entry of pathogens into the intestinal tract. Bicarbonate and citrate also interfere with the coagulation of milk, which is a concern in lactating calves (Naylor et al., 2006). Although Meganck et al. (2014) concluded, that feeding with products containing bicarbonate or citrate does not affect milk clotting in vivo and disagrees with general recommendations to not feed with these products concurrently with or short before/after cow's milk to calves.

Although sodium bicarbonate is the agent of choice for correction IV of acidemia, other alkalizing sodium salts precursors of bicarbonate are also used; but they do not have their drawbacks in over dosage, which are both source of $\mathrm{HCO}_{3}^{-}$and energy, including L-sodium lactate and sodium acetate (Kasari and Naylor, 1986; Alonso et al., 2001; Naylor et al., 2006; Alonso et al., 2008a; Smith, 2009; Meganck et al., 2014). Sodium lactate has a progressive alkalizing effect, provided they have obtained the integrity of liver function, which is rare in an affected calf with severe diarrhea. Thus, the application of a solution containing lactate, whose Disomer is not physiological and therefore is not metabolized or if so very slowly, it is contraindicated in an hypovolemic calf (Alonso et al., 2008b). Seems that sodium acetate oral solutions are more effective in expanding the plasma volume than sodium bicarbonate oral solutions, although there was considerable calf-tocalf variability (Sen et al., 2009). Nevertheless, clinically important differences in the resuscitative response of oral replacement therapy with solutions $(300$ or $150 \mathrm{mmol}$ $\mathrm{L}^{-1}$ ) of sodium acetate or sodium bicarbonate were not identified (Sen et al., 2009). Sodium acetate has the advantage of metabolizing faster in the liver and other tissues (unlike lactate), it also has the advantage of vasodilator effects, allowing irrigation of peripheral and splanchnic tissues (Alonso et al., 2008a; Smith, 2009). Several important questions still need to be answered about the correction of D-lactic acidosis. One of the more important is whether or not correction of acidemia speeds the clearance of D-lactate. Conventional IV fluid therapy with saline and sodium bicarbonate given in accordance with the preceding principles has been shown to rapidly correct hyper D-lactatemia in diarrheic calves (Ewaschuk et al., 2006). This is also associated with the excretion of D-lactate in urine (Ewaschuk et al., 2006). In a controlled trial in calves with the acidosis without dehydration syndrome sodium bicarbonate was more effective than an equal volume of saline in correcting CNS depression suggesting that sodium bicarbonate therapy helps speed removal of D-lactate (Kasari and Naylor, 1986; Naylor et al., 2006).

As mentioned earlier, bicarbonate losses or $\mathrm{H}^{+}$gains are likely to be ongoing and considerably more bicarbonate may be required than at first calculated. This is especially true in older calves, where acidosis is due in part to the production of acids in the colon (Grove-White, 1994). In 
these cases, applying fluid with bicarbonate is beneficial, provided that the acid-base status has been previously measured and during therapy. Grove-White (1994) recommends the addition of 400 to $800 \mathrm{mmol}$ of sodium bicarbonate to 5 litres of fluid, being safe and effective in severely acidotic calves.

\section{Major Digestive Diseases and their Treatment by Fluid Therapy}

Most electrolyte imbalances are due to a net loss of electrolytes caused by diseases of the digestive system. Sweating, bleeding wounds from burns, excessive salivation and vomiting are also accompanied by loss of electrolytes, but are unimportant in ruminant animals (Dirksen et al., 2005; Radostits et al., 2007).

\section{Neonatal Diarrhea in Calves}

While diarrheal diseases can appear at any age in ruminants, it is in young animals, calves, lambs and kids, where neonatal diarrhea is the most common cause of death, being a major cause of economic losses to the livestock industry (Smith and Berchtold, 2014).

Diarrhea in new-born calves remains the leading cause of morbidity and mortality (Berchtold, 2009). It is a complex disease that occurs predominantly during the first weeks of life, with multiple causes among which include viruses (rotavirus, coronavirus), bacteria (Escherichia coli, Salmonella sp.), protozoa (Cryptosporidium parvum, Eimeria sp.) or errors in feeding and management (Radostits et al., 2007; Berchtold, 2009).

Regardless of the pathogen or the mechanism involved, this disease is characterized by increased loss of electrolytes and water in the faeces of calves and often decreases milk intake (Smith and Berchtold, 2014). Regardless of the cause, it is necessary to establish a treatment protocol that includes antibiotics (although the origin is not initially bacterial, diarrheal stool favour the growth of a large number of pathogens), anti-toxic, antiparasitic and especially correct dehydration and reverse the acid-base and electrolyte changes produced.

This process causes dehydration, strong acidosis, electrolyte abnormalities (usually decreased sodium, chlorides, increased or decreased potassium and to a lesser extent magnesium), increased levels of D-lactate and a negative energy balance (by anorexia and malabsorption of nutrients).

Therefore, diarrhea is by far the most common indication for fluid therapy in neonatal calves (Alonso et al., 2001; Smith and Berchtold, 2014). It is necessary to note that acidosis is the most important disorderin calves that this along with dehydration, are the triggers that cause the fatal evolution of the process (Alonso et al., 2008b); however there is the possibility of finding clinically ill calves with minimal or no signs of dehydration, the socalled "acidosis-without-dehydration-syndrome" (Berchtold, 2009).

\section{Pathophysiology of Disorders}

Alteration of secretion and absorption mechanisms are essential in the pathophysiology of diarrhea. The continuous flow of water and electrolytes through the intestinal mucosa, either through absorption or secretion, may be altered in greater or lesser degrees by the causes that provoke diarrhea (Zurita et al., 1987; McClure, 2001; Meganck et al., 2014). Regardless of origin, most calves with diarrhea show an increased number of coliform bacteria in the small intestine (bacterial overgrowth), which contributes to morphological damage of the intestinal mucosa and may result in increased susceptibility to bacteremia. Metabolic acidosis is a frequent consequence of gastrointestinal disease and is in calves with dehydration and in clinically sick calves, with minimal or no signs of dehydration, the so-called "acidosis-without-dehydration syndrome" (Berchtold, 2009; Meganck et al., 2014).

Dehydration causes diarrheain calf with a significant decrease in extracellular volume, which is of particular importance at the level of plasma compartment (hypovolemia) and a slight increase in intercellular volume. During diarrhea, there is a loss of sodium, potassium, chloride and bicarbonate faeces, with a decrease in plasma sodium concentration; resulting in extracellular hypoosmotic fluid (hyponatremia), which makes water pass to the intracellular space, increasing its volume (Rejas and Alonso, 2008). A calf with diarrhea has water loss up to $100 \mathrm{~mL} \mathrm{~kg}^{-1}$ body weight (4000$5000 \mathrm{~mL}^{-1}$ ) (Alonso et al., 2008a). Contrary to what one might think, hyponatremia is observed rather than hypernatremia, this is due to water retention by the kidneys that occurs in response to Ant Diuretic Hormone $(\mathrm{ADH})$, released as a result of hypovolemia. $\mathrm{ADH}$ and thirsty, regulates the plasma sodium concentration, so that changes in serum sodium variations indicate water rather than sodium. Sodium loss is primarily extracellular, plasma sodium drop causes the flow of water into the intracellular space, decreasing extracellular volume (Rejas and Alonso, 2008); also the intracellular environment may be affected because of metabolic acidosis producing a $\mathrm{Na}^{+} / \mathrm{H}^{+}$exchange between the intracellular and extracellular spaces (Alonso et al., 2008b). Also, the loss of bicarbonates as $\mathrm{HCO}_{3}{ }^{-}$takes increased production of $\mathrm{H}+$ ions, causing extracellular acidosis and intracellular subsequently (Alonso et al., 2008a).

From the metabolic point of view, the acidosis is the most important disorder, along with dehydration are the triggers that provoke the fatal evolution of the process (Alonso et al., 2001). Several factors predispose animals with diarrhea to metabolic acidosis. Among them we can mention 1. Excessive loss of bicarbonate in the faeces, 2. Dehydration, leading to hypovolemia and low perfusion in tissues, 3. Anaerobic metabolism at a muscular level, which causes increased production of lactic acid, 4. Acid 
production of abnormal intestinal flora (dysbiosis) and 5. Low renal perfusion, leading to a decreased excretion of $\mathrm{H}^{+}$and lower production of $\mathrm{HCO}_{3}{ }^{-}$, the kidney is the largest body forming $\mathrm{HCO}_{3}{ }^{-}$(Rejas et al., 2001; Alonso et al., 2008b).

An important discovery was that metabolic acidosis in diarrheic calves varies during the first weeks of life. This has been pointed out that metabolic acidosis is less severe during the first week of life, than in diarrheic calves older than 8 days (Naylor et al., 2006; Smith and Berchtold, 2014). Those calves over 1 week of life can produce high levels of organic acids in the large intestine, as a result of bacterial growth, so these calves often suffer more severe acidosis. Subsequent studies confirmed that in calves with diarrhea over 1 week old, base deficit usually was almost twice that in calves with diarrhea occurring during the first week of life (Meganck et al., 2014; Smith and Berchtold, 2014).

These patients show signs of mental depression, weakness and anorexia, which may result from dehydration, acidemia, endotoxaemia or sepsis, although there is evidence that the isomer D-lactate plays an important role in its development. Recent studies have linked the degree of depression of calves with increasing concentration of D-lactate instead of only the severity of acidosis or dehydration (Naylor et al., 2006; Berchtold, 2009; Lorenz et al., 2005; Meganck et al., 2014; Smith and Berchtold, 2014). Derivatives clinical signs of increasing concentrations of D-lactate and its relation to predicting acidemia in calves are described elsewhere in this chapter.

The D-lactate is primarily responsible for the acidosis of individuals with severe diarrhea, since cells metabolize lactate with difficulty; it accumulates in the blood faster than the L-isomer (Lorenz et al., 2005; Rejas and Alonso, 2008; Meganck et al., 2014).

Acidosis is also important; as it affects intra- and extracellular concentrations of potassium, favouring the movement of potassium from the cells into the extracellular fluid and causing hyperkalemia. Although significant loss of potassium with faeces occur in calves with diarrhea and that their intake is reduced, these animals can have a normal or elevated serum potassium.

Hyperkalemia is attached to the phenomenon of uncompensated metabolic acidosis and $\mathrm{H}^{+}$ions penetrate into the intracellular compartment and cause the output of $\mathrm{K}^{+}$ions into the extracellular sector to maintain electro-neutrality (Alonso et al., 2008a). Moreover, hypovolemia favours greater loss of potassium via the kidneys, caused by aldosterone (Rejas and Alonso, 2008). Therefore, kalemia does not reflect the real deficit of potassium in a calf with diarrhea. Thus diarrheic calf with severe dehydration and acidosis uncompensated, has a negative level of potassium, although hyperkalemia appears and potassium intake is necessary (Alonso et al., 2008b). Potassium loss is difficult to assess clinically; intracellular potassium loss associated with hyperkalemia, disturbs the functioning of the heart and skeletal muscles, causing weakness, lethargy, arrhythmia and bradycardia (Alonso et al., 2008a) and the electrocardiogram little amplitude level and absence of the $\mathrm{P}$ wave is observed (Alonso et al., 2008b).

There is also a hypoglycemia due to both anorexia and the lack of intestinal absorption. The increase of uremia, present in many animals, is a consequence of increased catabolism and decreased urine output. The elevation of uremia seems to be one of the earliest plasmatic variables in diarrhea in young ruminants. So much so, that Fayet and Overwater, consider that the assessment of uremia, chloremia and hematocrit allow a prognosis to be issued and estimate the effectiveness of the treatment (Alonso et al., 2008a).

\section{Fluid Therapy in Diarrhea of Calves}

Fluid therapy is perhaps the most important aspect in the therapy of calves with diarrhea, as the most common cause of death is dehydration and acidosis. There are multiple studies that certify that the prevention and correction of these alterations significantly improves the survival of these animals. Therefore the objectives are: 1. Correct dehydration and electrolyte imbalances, 2. Correct acidbase deficits (reduce levels of D-lactate), 3. Provide nutritional support and 4. Remove and/or prevent possible bacteremia (Smith and Berchtold, 2014). Three of these goals are covered by fluid therapy (Alonso et al., 2008b; Berchtold, 2009; Smith and Berchtold, 2014).

Restitution of water and electrolytes should be initiated early and without waiting for the onset of symptoms of dehydration. The amount of fluids to be administered should be calculated from the degree of dehydration, maintenance needs and losses that could occur in the near future. The amount of liquid to be perfused, as well as the rate and the route of administration is noted in a previous section. The conditions in which calves with diarrhea are and especially their clinical signs or blood measurements, will be considered in order to opt for one or the other infusion line; and for the right kind of fluids for the disease.

Oral hydration is an easy method of execution, economic, widespread, with good results and does not require special training of staff (Zurita et al., 1987). There are multiple oral preparations in the market, generally in powder form to be dissolved in water, containing sodium, potassium, chloride and glucose. Sometimes citrates and glycine are added to facilitate the absorption of electrolyte. The presence of glucose represents an energy intake, but can only meet a fraction of the energy required by the calf (Meganck et al., 2014). Although there is considerable controversy regarding the use of breast milk and milk replacers in diarrheic calves, several studies recommend maintaining the milk supply, sometimes supplemented with oral 
rehydration solutions, because it improves the energy balance of the calf and facilitates the recovery of the intestinal mucosa (Zurita et al., 1987; McClure, 2001; Alonso et al., 2008a; 2008b; Smith, 2009; Meganck et al., 2014). The administration of liquids is easy when the calf is standing and alert, however weakened animals and/or prostrated represent a significant risk. It is important to avoid rapid administration because of the possibility of deriving liquid to the airway, therefore bottle-feeding, esophageal probes, or bottles partially introduced in the mouth, are often used.

It is recommended to administer quantities of less than two litres each time to prevent gastric distention and reflux into rumen. Thus recommended intakes are separated by at least $2 \mathrm{~h}$ and at least 3-4 times a day; which favoursa greater intake of liquid by the animal. A positive development of clinical signs should be seen within $48 \mathrm{~h}$ and once the animal restarts voluntary water intake, it is interesting to reduce the volume of rehydration solutions, administered orally.

Parenteral hydration should be considered in valuable animals, or calves with a severe clinical profile. Its main advantages are the rapid distribution of water and electrolytes, greater choice of more complete solutions and a faster clinical response. The most commonly used solutions are isotonic solution of 5\% glucose, which provides energy and water, Lactate Ringer's solution, which it is able to cover -albeit minimally- the sodium, potassium, bicarbonate deficits and mild acidosis (Zurita et al., 1987). Lactate Ringer's solution, which is able to cover -even minimally- the deficit sodium, potassium, bicarbonate and mild acidosis (Zurita et al., 1987). In more severe cases be necessary to use alkalizing solutions, as indicated in this article.

Alkalizing fluids are the right choice for IV rehydration of calves with diarrhea and dehydration. Currently, sodium bicarbonate is recommended for this treatment solution. Sodium bicarbonate (either hypertonic or isotonic) quickly corrects both acidosis and dehydration and restores normal cell function (Smith and Berchtold, 2014). In Müller's opinion, the sodium gluconate is ineffective in correcting acidemia and a solution containing sodium bicarbonate is much more effective in alkalinizing diarrheic calves with strong ion acidosis than a solution with sodium gluconate (Müller et al., 2012). When the calf's sucking reflex is restored, additional treatment may be administered orally (Smith and Berchtold, 2014). The age of the calf should be taken into account when assessing the severity of acidosis and to determine the requirements of bicarbonate in diarrheal calves. Acidosis may be present in sick calves with diarrhea, with or without dehydration, who cannot stand, they are lying or unstable, listless or in a coma, with incomplete or absent palpebral reflex. Also, if the sucking reflex is absent or weak, or calf is chewing erratically rather than sucking normally, D-lactic acidosis may be present in these animals (Smith and Berchtold, 2014).
Although there are four routes for parenteral administration: intravenous, subcutaneous, intraperitoneal and intraosseous (Constable, 2003); the first two are used in bovine clinical and to choose one or the other depends on the degree of involvement of the animal and practical possibilities for therapy. Nor is there an exact rule for administration of fluid; treatment response being the best guide to assess the amount of liquid needed to perfuse (Grove-White, 1994). The recommended infusion rate is 20 to $40 \mathrm{~mL} \mathrm{~g}^{-1} \mathrm{~h}$, trying to correct dehydration in about 6 to $8 \mathrm{~h}$ and then gradually the remaining fluids administered required for maintenance and expected losses (Naylor et al., 2006); but especially in heavily affected animals can be increased infusion rate. This and other aspects have been listed in the relevant chapter.

\section{Ruminal Acidosis/Lactic Acidosis for Ruminal Overload}

The clinical symptoms vary depending on the duration and volume of production of lactic acid, ranging from a temporary loss of appetite to severe gastrointestinal symptoms, with significant involvement of the general condition (Dirksen et al., 2005). The disease occurs as a result of excessive consumption of food or rations rich in carbohydrates easily digestible, especially starch and/or sugars, simultaneously with a poor amount of fiber (Lisboa, 2004; Dirksen et al., 2005). In rare cases, it can be told that recently the animal has escaped, has had access and has ingested a large quantity of such food (Lisboa, 2004; Dirksen et al., 2005).

Lactic acid is generated in excess as a final product of altered rumen microbial fermentation. These carbohydrates which are easily digestible cause a significant production of volatile fatty acids, especially lactic acid, which causes a significant drop in ruminal $\mathrm{pH}$. The lactic acid concentration rises above $100 \mathrm{mmol}$ $\mathrm{L}^{-1}$, reaching in extreme cases above $300 \mathrm{mmol} \mathrm{L}^{-1}$, synthesized lactic acid ( $\mathrm{L}$ and $\mathrm{D}$ isomers). Both isomers are physiological metabolites of ruminal content and even can be checked in a diet with coarse food.

The production of either isomer is determined in many cases for food and microorganisms in the rumen, so ruminal $\mathrm{pH}$ changes may alter the microbial flora significantly and therefore their concentrations vary. Thus D-lactic isomer increases during acidosis, from $20 \%$ at $\mathrm{pH} 6$ up to $50 \%$ at pH 5 (Dirksen et al., 2005). This is of great importance, because the D-lactic acid is metabolized in an inferior form; and therefore more slowly than the L-isomer and that its elimination is primarily by renal excretion (Dirksen et al., 2005).

When ruminal acidosis is severe, it ends up causing an acid-base systemic imbalance, characterized by hyperlactataemia, since a large amount of lactic acid is absorbed (Lisboa, 2004; Dirksen et al., 2005; Radostits et al., 2007; 
Alonso et al., 2008a). It is important to note that lactate is 10 times stronger than the volatile fatty acids, so it exceeds the buffer capacity of the rumen fluid and saliva (poorly produced if dehydration). Ruminal acidosis also produces a progressive inhibition of motor activity of the rumen, causing paralysis when the $\mathrm{pH}$ is about 5 (Alonso et al., 2008b). Systemic lactic acidosis may eventually be accompanied by varying degrees of dehydration (Lisboa, 2004). Increasing the osmolarity of ruminal fluid additionally promotes a flow of water in the light of organs, besides the lactic acid that is conveyed to the intestine causes an osmotic diarrhea, which further aggravates dehydration and electrolyte imbalance (Alonso et al., 2008a).

\section{Treatment of Lactic Acidosis}

In addition to multiple measures to empty the ruminal content, to modify the microbial flora, to restore intestinal motility and proventriculi and other supportive therapies must be balanced hemoconcentration and blood acidosis (Tufani et al., 2013; Dirksen et al., 2005; Alonso et al., 2008b; Radostits et al., 2007). Fresh ruminal cud from slaughter house was collected and transplanted into rumen (Tufani et al., 2013). If the overload is severe, it is necessary to empty the ruminal content either by rumenotomy or by siphoning. Afterwards ruminal and metabolic acidosis will be corrected by alkalizing agents administered orally or parenterally, according to the symptoms (Tufani et al., 2013; Radostits et al., 2007). Alkalizing used in the rumen are $\mathrm{Mg}$ salts (oxide or sulfate, $1 \mathrm{~g} \mathrm{~kg}^{-1}$ ) or sodium $\left(0.5 \mathrm{~g} \mathrm{~kg}^{-1}\right)$ bicarbonate, in plenty of warm water by gavage or by rumenotomy (Tufani et al., 2013; Alonso et al., 2008a). Alkalizing in rumen isn't always recommended, because if the amount administered is not calculated correctly alkalosis can be caused (Alonso et al., 2008b).

Animals that die in the first phase of the disease do so primarily as a result of blood decompensated acidosis, hypovolemia, shock and disseminated intravascular coagulation (Dirksen et al., 2005, 398). Therefore to achieve a positive evolution of the disease it is often decisive to maintain fluid homeostasis and acid-base balance; this is also very important because the excretion of lactic acid is mostly done by the kidney (Dirksen et al., 2005). Whenever circumstances permit fluid replacement it should be done by a continuous intravenous drip; it is suitable for the mixture of physiological saline and sodium bicarbonate $(\mathrm{NaCl}$ $0.9 \%+$ sodium bicarbonate, $1.4 \%=4.5 \mathrm{~g} \mathrm{NaCl}+6.5 \mathrm{~g}$ $\left.\mathrm{NaHCO}_{3} / \mathrm{L}\right)$ or only bicarbonate solutions at 1.4 or $5 \%$ (Dirksen et al., 2005). Radostits et al. (2007) recommend treating systemic acidosis by intravenous solutions sodium bicarbonate $5 \%$, with a rate of 5 litres to an animal of $450 \mathrm{~kg}$, for an initial period of $30 \mathrm{~min}$. Then $1.3 \%$ sodium bicarbonate is administered at a rate of 150 $\mathrm{ml} \mathrm{kg} \mathrm{kW}^{-1} \mathrm{BW}$, intravenously for the following 6-12 $\mathrm{h}$
(Radostits et al., 2007). In sheep and goats, therapeutic measures consisted of neutralization of acidity by oral and/or parenteral use of isotonic $(1.3 \%)$ and hypertonic (5\%) sodium bicarbonate with adequate fluid therapy (Tufani et al., 2013). Thus, it has been used 5\% sodium bicarbonate solution at $10 \mathrm{~mL} \mathrm{~kg}$, along with a balanced electrolyte solution $(100 \mathrm{~mL} \mathrm{~kg}$ ) and $1.3 \%$ solution of sodium bicarbonate at $50 \mathrm{~mL} \mathrm{~kg}^{-1}$ in severe case, or isotonic sodium bicarbonate $(1.3 \%), 50 \mathrm{~mL} \mathrm{~kg}^{-1}$ intravenously in moderate cases (Tufani et al., 2013).

Because the gastrointestinal contents hyperosmolarity and enteric water loss through diarrhea, oral fluid supply does not serve to recover the lost fluids. Cattle that responds favorably to rumenotomy and the fluid has increased muscle strength, he begins to urinate after one $h$ and try to remain standing after 6 to $12 \mathrm{~h}$ (Radostits et al., 2007). The general rule recommends to correct half of the initial deficit of bicarbonate in the first $6 \mathrm{~h}$ and the other half in the next 6-18 h. The bicarbonate deficit ranges between 12 and $20 \mathrm{mmol} \mathrm{L}^{-1}$ (Alonso et al., 2001). We must also not forget that once the animal recovers, the reuse of ruminal lactate provides an additional force of bicarbonate; thus the risk of overload alkaline intensifies (Alonso et al., 2001).

The criteria for calculating the intravenous infusion of bicarbonate as alkalizing would be given by the formula: Deficit $(\mathrm{mmol} / \mathrm{L}) 0.3 \times$ body weight $(\mathrm{kg})$, where 0.3 is the extracellular space (equivalent to $30 \%$ $\mathrm{BW})$ and an infusion rate of $2.5 \mathrm{mmol} \mathrm{kg} \mathrm{kW}^{-1} \mathrm{BW}$ (Alonso et al., 2008a). As an example for a cow with $500 \mathrm{~kg}$, with a deficit of $15 \mathrm{mmol} \mathrm{L}{ }^{-1}$, would require $2250 \mathrm{mmol}$ bicarbonate $(15 \times 0,3 \times 500)$, equivalent about 14 litres of bicarbonate $1.3 \%$ and about 2.25 litres of bicarbonate $8.4 \%$ (Table 3 ). The recommended infusion rate is $2.5 \mathrm{mmol} \mathrm{kg} \mathrm{gW}^{-1} \mathrm{BW}$ hour.

\section{Subclinical Ruminal Acidosis}

Subclinical ruminal acidosis is due to intensive production of volatile fatty acids with temporary increases lactic acid. The main causes are diets with high concentrations of easily fermentable carbohydrates or as a consequence of certain organic and metabolic diseases (Dirksen et al., 2005). As a general rule, it does not require fluid, nor orally nor parent rally. Correction of ruminal acidosis by administering alkalizing agents, with plenty of warm water and orally as indicated above, is usually sufficient. The substances used are salts of $\mathrm{Mg}$ or sodium bicarbonate (Radostits et al., 2007).

\section{Abomasal Displacement}

The imbalance of fluid, electrolyte and acid-base is the consequence of the difficulty of abomasal transit and retention of liquids in the light of displaced abomasum, because emptying is prevented or delayed and the resulting ions are continuously secreted and don't undergo the physiological process of intestinal resorption. 
Table 3. Severity of acidosis (Grove-White, 1994, 266).* equivalent to plasma bicarbonate

\begin{tabular}{ll}
\hline Severity of acidosis & $\mathrm{TCO}_{2}^{*}(\mathrm{mmol} / \mathrm{L})$ \\
\hline Normal & $24(21-28)$ \\
Mild acidosis & $16.5-21.0$ \\
Moderate acidosis & $12-16$ \\
Severe acidosis & $8-12$ \\
Very severe acidosis & $<8$ \\
\hline
\end{tabular}

Therefore, the retention of large amounts of ions $\mathrm{Ca}^{2+}, \mathrm{Na}^{+}, \mathrm{H}+, \mathrm{K}^{+}$and $\mathrm{Cl}^{-}$occurs. This liquid is very rich in $\mathrm{Cl}^{-}$ions which combine with $\mathrm{H}^{+}$ions secreted to generate $\mathrm{HCl}$. For every $\mathrm{H}^{+}$secreted inside the abomasum a ion $\mathrm{HCO}_{3}^{-}$it is generated and returned to the extracellular fluid compartment (Lisboa, 2004; Dirksen et al., 2005; Radostits et al., 2007; Alonso et al., 2008b). Thus, dehydration is accompanied by metabolic alkalosis, with hypochloremia and hypokalemia, possibly there hyperglycemia (Rejas et al., 2001; Lisboa, 2004; Dirksen et al., 2005; Radostits et al., 2007) and even possible hypocalcemia (Dirksen et al., 2005). $\mathrm{K}^{+}$ depletion is due to increased disposal in the urine, as a compensatory mechanism renal alkalosis (exchange of $\mathrm{H}^{+}$ retained or to maintain electrical neutrality for the elimination of $\mathrm{HCO}_{3}$ ) (Alonso et al., 2008a).

\section{Abomasal Displacement to the Left}

Surgical correction through various techniques or procedures of dump, with or without restraint, to settle a dystopia of abomasum with varying degrees of success. Treatment of secondary ketosis, accompanying this digestive pathology, requires parenteral administration of dextrose and oral administration of sodium propionate or propylene glycol.

In abomasal displacement to the left, may be varying degrees of dehydration, metabolic alkalosis, hypokalemia, hypochloremia and (Radostits et al., 2007); therefore ideally it makes blood valuations, although balanced electrolyte solutions containing sodium, chloride, potassium, calcium and glucose intake is sufficient in most cases (Radostits et al., 2007).

In mild cases, with minimal systemic disorders, in which a light hemoconcentration and metabolic alkalosis is observed, early treatment with fluids and electrolytes orally or intravenously can give good results. Fluid therapy is essential to restore digestive motility, especially when the abomasum is distended for accumulation of fluid, requiring the transit of content into the duodenum to be started in order for the electrolytes which it contains to be absorbed.

It is recommended to mix 2 litres of physiological saline +1 litre of isotonic solution of $1.1 \% \mathrm{KCl}+1$ litre of isotonic solution of $5 \%$ dextrose intravenously at a rate of 4 to $61 \mathrm{~h}$. Metabolic alkalosis is corrected using sodium chloride solutions at different concentrations $(0.9,3.6$ and $7.2 \%)$, with no significant differences in outcomes (Radostits et al., 2007).

Acidifying solutions are isotonic solutions that mainly consist of potassium chloride and ammonium chloride ( $108 \mathrm{~g}$ of potassium chloride $+80 \mathrm{~g}$ of $\mathrm{NH}_{4} \mathrm{Cl}$ in $20 \mathrm{~L}$ of water), providing a source of potassium and chloride to correct alkalosis. This solution can be administered intravenously at a rate of $20 \mathrm{~L}$ in $4 \mathrm{~h}$ to $450 \mathrm{~kg}$ cows; followed by administration of a balanced electrolyte solution at dose of 100 to $150 \mathrm{~mL}$ $\mathrm{kg}^{-1} \mathrm{BW}$ in a $24 \mathrm{~h}$ period.

The latter acidifying solution should be used carefully, it is necessary to make periodic blood assessments and ideally every hour to prevent acidosis (Radostits et al., 2007). Treatment with oral electrolytes is recommended primarily in the postoperative period (Radostits et al., 2007). A mixture of $\mathrm{NaCl}$ (50 to $100 \mathrm{~g}$ ), $\mathrm{KCl}(50 \mathrm{~g})$ and $\mathrm{NH}_{4} \mathrm{Cl}(50$ to $100 \mathrm{~g})$ is administered every $24 \mathrm{~h}$; along with parenteral fluid if necessary. Supplementation with $50 \mathrm{~g} /$ day of $\mathrm{NaCl}$ may be continued until the cow returns to normal appetite (Radostits et al., 2007).

Sometimes, supplementation with $500 \mathrm{~mL}^{-1}$ of $25 \%$ calcium borogluconate intravenously is recommended, the rationale is that the administration of calcium enhances the motility of the abomasum (Radostits et al., 2007).

\section{Abomasal Displacement to the Right, with or without Torsion}

In displaced abomasum to the right, with much lower prevalence, the condition described above is complicated by hypovolemic shock and end toxemic shock, due to vascular compromise and areas of ischemic necrosis, especially when there is torsion of the viscera. In these situations and with the advancement of the process, lactic acidosis beats the original alkalosis (Lisboa, 2004).

It is recommended the examination of blood for alkalosis/acidosis determination to ensure the diagnosis and the possible evolution of the disease. Because of the retention of hydrochloric acid markedly increase blood parameters indicators of alkalosis $\left(\mathrm{pH}, \mathrm{pCO}_{2}, \mathrm{HCO}_{3}^{-}\right.$, positive $\left.\mathrm{BE}\right)$, while clearly concentrations of chlorine and potassium descend. Simultaneously hematocrit, hemoglobin and urea levels increase, indicating hem concentration and limited function renal. In an advanced stage, alkalosis is overwhelmed by a metabolic acidosis, which is recognized by the drop in $\mathrm{pH}, \mathrm{pCO}_{2}, \mathrm{HCO}_{3}{ }^{-}, \mathrm{BE}(<+5$ mmol L ${ }^{-1}$ ) in blood, whereas there is little change in the concentrations of chloride, potassium and urea (Dirksen et al., 2005). 


\begin{tabular}{llllll}
\multicolumn{7}{l}{ Table 4. Composition of the main crystalloid solutions used in fluid therapy. *lactate] } \\
\hline
\end{tabular}

Regarding the pre and postoperative therapy, if the patient's general condition is markedly affected it can be deduced, without a blood analysis, that hypovolemia, metabolic alkalosis and other consequences have occurred resulting from the disorder in the gastrointestinal tract. These patients should receive preoperatively several litres of intravenous physiological saline, which serves not only to bring the patient to an operable state, but to prevent a probable circulatory disorder that occurs during the replacement. For postoperative treatment of severe cases it is advisable drip infusion of physiological saline equivalent to $3 \%$, maximum $5 \%$ (depending on state) of body weight in the first 24-48 h. In milder cases blood status is normalized in 24-48 h, without an intravenous infusion, as long as bowel function is resumed (Dirksen et al., 2005).

\section{Overload and Abomasal Dilatation}

In addition to the treatment for the primary disease, special importance to the parenteral fluid and correction of acid-base balance should be given. Hypertonic oral rehydration solutions have the theoretical disadvantage that they may create a transient dehydration after feeding because the hypertonicity of abomasal fluid contents can cause movement of water from the extracellular space into the abomasum (Sen et al., 2009). Successful results with the following treatment have been obtained: Starting with intravenous drip of $1 \mathrm{~L}$ of sodium chloride $7.2 \%$, followed by $20 \mathrm{~L}$ of physiological saline with $50 \mathrm{~g}$ $\mathrm{L}^{-1}$ glucose and $80 \mathrm{mmol}$ of potassium chloride. On the 2nd and 3rd day post-surgery it is recommended to apply 10 L of physiological saline intravenous glucose (Dirksen et al., 2005; Smith, 2009).

\section{Vagal Indigestion Syndrome}

Vagal indigestion and other causes, mainly has its origin in two etiologies, vagus nerve injury and reticulated adhesions. Following the functional obstruction and distension an abomasal fluid retention occurs in this viscera and a backflow of its contents into the rumen leading to a ruminal chloride concentration $>20 \mathrm{mmol} \mathrm{L}^{-1}$. Therefore you can observe varying degrees of dehydration and metabolic alkalosis leading towards hypochloremic and hypokalemia (Radostits et al., 2007). In the previous stenosis the abomasal fluid can reach the duodenum and in that case neither metabolic alkalosis nor dehydration occur (Radostits et al., 2007).

Washing the rumen, when it appears significantly distended, not only relieves the pressure but also allows greater ease for scanning the abdomen (Radostits et al., 2007). Some animals respond adequately to the administration of fluids and electrolytes, in combination with oral administration of mineral oil (5 to 10 litres daily for 3 days) or docusate sodium (Radostits et al., 2007). The use of a hypertonic saline $1.8 \%$ is effective for correction of metabolic alkalosis hypochloremic experimentally induced in sheep and could be useful in cattle (Radostits et al., 2007).

\section{Intestinal Obstruction Dilation and Cecal Volvulus}

The cecal dilation primarily affects cattle milk yield during early lactation. Clinically it is characterized by loss of appetite, decreased milk production, fewer stools, detection of high-pitched sounds in the upper right flank and the detection of the distended viscera on rectal examination. Intestinal obstruction is manifested clinically with anorexia, abdominal pain, absence of stools, dark faecal shedding with blood and mucus, dehydration with acid-base imbalance and the death of the animal when no physical obstruction is properly resolved. Surgical correction is the only treatment in those animals in which recovery is sought (Radostits et al., 2007).

Among the support measures it is of great importance that a fluid and electrolyte therapy adapted to the degree of dehydration, be applied by continuous drip and if not possible by repeated intravenous applications (Dirksen et al., 2005). Physiological saline solutions with a possible addition of 10 to 20 $\mathrm{mmol}$ of potassium/L are suitable; usually it is achieved by applying half of the calculated according to the degree of dehydration in the term of 5 to $10 \mathrm{~h}$; because with the restart of the intake passage absorption processes help in normalizing (Dirksen et al., 2005).

Multiple electrolyte solutions with physiological saline are effective, even though the animal has metabolic alkalosis with hypokalemia and hypochloremia (Radostits et al., 2007). The fluid and electrolytes intravenously are always needed in the postoperative period and may also be needed preoperatively. 
After obstruction of the small intestine caused by a hairball in 2 young beef calves, were administered of $7.2 \mathrm{~L}$ of normal saline $(0.9 \% \mathrm{NaCl}), \mathrm{IV}$, over the first $36 \mathrm{~h}$, plus one liter of lactated Ringer's solution and 3.6 L of normal saline were given during the surgery and for the next $24 \mathrm{~h}$, with positive results (Abutarbush and Radostits, 2004).

\section{Acknowledgement}

We are grateful to Fiona Hickey for the linguistic revision of this paper.

\section{Author's Contributions}

All authors equally contributed in this work.

\section{Ethics}

This review article is original and its contents have not been published before. No ethics issues are concerned with the present article.

\section{References}

Abutarbush, S.M. and O.M. Radostits, 2004. Obstruction of the small intestine caused by a hairball in 2 young beef calves. Canad. Vet. J., 45: 324-325.

Alonso, D., J. Ángel, R. López and Juan, 2008a. Fluidoterapia práctica en rumiantes. RECVETRevista Electrónica de Clín. Vet., 3: 1-18.

Alonso, D., J. Ángel, R. López and Juan, 2008b. Procesos entéricos en vacunos. RECVET-Revista Electrónica de Clínica Vet., 3: 1-14.

Alonso, D.A.J., L.E. Fidalgo Álvarez and J.R.G. Montaña, 2001. Fluidoterapia en Medicina de Rumiantes. In: Aplicaciones de Fluidos en Veterinaria, Rejas J., L.E. Fidalgo, A. Goicoa and J.R. González (Eds.), Consulta de Difusión Veterinaria, Valencia, Spain, pp: 111-128.

Berchtold, J., 2009. Treatment of calf diarrhea: Intravenous fluid therapy. Vet. Clin. North Am. Food Anim. Pract., 25: 73-99. DOI: 10.1016/j.cvfa.2008.10.001

Bjorling, D.E. and C.A. Rawlings, 1983. Relationship of intravenous administration of Ringer's lactate solution to pulmonary edema in halothaneanesthetized cats. Am. J. Vet. Res., 44: 1000-1006.

Booth, A.J. and J.M. Naylor, 1987. Correction of metabolic acidosis in diarrheal calves by oral administration of electrolyte solutions with or without bicarbonate. J. Am. Vet. Med. Assoc., 191: 62-8.

Broaddus, V.C., J.P. Wiener-Kronish and N.C. Staub, 1990. Clearance of lung edema into the pleural space of volume- loaded anesthetized sheep. J. Applied. Physiol., 68: 2623-2630.
Constable, P.D., 2003. Fluid and electrolyte therapy in ruminants. Vet. Clin. North Am. Food Anim. Pract., Philadelphia, 19: 557-597. DOI: 10.1016/S0749-0720(03)00054-9

Constable, P.D., E. Thomas and B. Boisrame, 2001. Comparison of two oral electrolyte solutions for the treatment of dehydrated calves with experimentally-induced diarrhea. Vet. J., 162: 129-140. DOI: $10.1053 /$ tvjl.2000.0553

Constable, P.D., P.G. Walker, D.E. Morin and J.H. Foreman, 1998. Clinical and laboratory assessment of hydration status of neonatal calves with diarrhea. J. Am. Vet. Med. Assoc., 212: 991-996.

Dirksen, G., H.D. Gründer and M.M. Stöber, 2005. Medicinainterna y Cirugía Del Bovino. 4th Edn., Inter-Médica, Buenos Aires, Argentina, pp: 1172.

Ewaschuk, J.B., G.A. Zello and J.M. Naylor, 2006. Lactobacillus GG does not affect d-lactic acidosis in diarrheic calves, in a clinical setting. J. Vet. Internal Med., 20: 614-619.

DOI: $10.1111 /$ j.1939-1676.2006.tb02905.x

Ewaschuk, J.B., J.M. Naylor and G.A. Zello, 2004. Dlactate production and excretion in diarrheic calves. J. Vet. Internal Med., 18: 744-747. DOI: $10.1111 /$ j.1939-1676.2004.tb02615.x

Gentile, A., I. Lorenz, S. Sconza and W. Klee, 2008. Experimentally induced systemic hyperchloremic acidosis in calves. J. Vet. Internal Med., 22: 190-195. DOI: $10.1111 /$ j.1939-1676.2008.0028.x

Gentile, A., S. Sconza, I. Lorenz, G. Otranto and G. Rademacher et al., 2004. D-Lactic acidosis in calves as a consequence of experimentally induced ruminal acidosis. J. Vet. Med. Series A, 51: 64-70. DOI: $10.1111 /$ j.1439-0442.2004.00600.x

Gottardo, F., S. Mattiello, G. Cozzi, E. Canali and E. Scanziani et al., 2002. The provision of drinking water to veal calves for welfare purposes. J. Anim. Sci., 80: 2362-2372. DOI:10.2527/2002.8092362x

Grove-White, D., 1994. Fluid therapy the neonatal calf. Practice, 16: 263-266. DOI: 10.1136/inpract.16.5.263

Halimi, M., S.I. Ahmed, M.T. Rai, 1991. Studies on experimental ruminal acidosis in calves fed with ragi slurry: 5. Haematological changes. Mysore J. Agric. Sci., 25: 236-238.

Hughes, D., 2001. Fluid therapy with artificial colloids: Complications and controversies. Vet. Anaesthesia Analgesia, 28: 111-118. DOI: $10.1046 / \mathrm{j} .1467-2995.2001 .00023 . \mathrm{x}$

Kasari, T.R. and J.M. Naylor, 1986. Further studies on the clinical features and clinic pathological findings of a syndrome of metabolic acidosis with minimal dehydration in neonatal calves. Canad. J. Vet. Res., 50: $502-508$.

Lisboa, J.A.N., 2004. Fluidoterapia emruminantes: Uma abordagem prática. Proceedings of the Congresso Paulista de Medicina Veterinária, Conselho Regional de Medicina Veterinária do Estado de São Paulo, (ESP' 04), Santos, Brasil, pp: 3-6. 
Lorenz, I., 2009. D-Lactic acidosis in calves. Vet. J., 179: $197-203$.

Lorenz, I., A. Gentile and W. Klee, 2005. Investigations of D-lactate metabolism and the clinical signs of Dlactataemia in calves. Vet. Record, 156: 412-415. DOI: $10.1136 / \mathrm{vr} .156 .13 .412$

McClure, J.T., 2001. Oral fluid therapy for treatment of neonatal diarrhea in calves. Vet. J., 162: 87-89. DOI: $10.1053 /$ tvj1.2001.0597

Meganck, V., G. Hoflack and G. Opsomer, 2014. Advances in prevention and therapy of neonatal dairy calf diarrhea: A systematical review with emphasis on colostrum management and fluid therapy. Acta Vet. Scandinavica, 56: 1-8. DOI: $10.1186 / \mathrm{s} 13028-014-0075-\mathrm{x}$

Müller, K.R., A. Gentile, W. Klee and P.D. Constable, 2012. Importance of the effective strong ion difference of an intravenous solution in the treatment of diarrheic calves with naturally acquired acidemia and strong ion (metabolic) acidosis. J. Vet. Internal Med., 26: 674-683. DOI: 10.1111/j.1939-1676.2012.00917.x

Naylor, J.M., 1999. Oral electrolyte therapy. Rev. Vet. Clin. North Am. Food Anim. Pract., 15: 487-504. DOI: 10.1016/S0749-0720(15)30160-2

Naylor, J.M., G.A. Zello and S. Abeysekara, 2006. Advances in oral and intravenous fluid therapy of calves with gastrointestinal disease. Proceedings of the 24th World Buiatrics Congress, (WBC' 06), Nice, France, pp: 139-50.

Radostits, O.M., C.C. Gay, K.W. Hinchcliff and P.D. Constable, 2007. Veterinary Medicine: A Textbook of the Diseases of Cattle, Horses, Sheep, Pigs and Goats. 10th Edn., WB Saunders, Philadelphia, USA, ISBN-10: 780702027772, pp: 2065.

Rainger, J. and A. Dart, 2006. Enteral fluid therapy in large animals. Australian Vet. J., 84: 447-451. DOI: $10.1111 / \mathrm{j} .1751-0813.2006 .00072 . x$

Rejas, L.J. and A.J.D. Alonso, 2008. Principios generales de fluidoterapia en rumiantes. RECVETRevista Electrónica de Clín. Vet., 3: 1-15.

Rejas, L.J., J.R.G. Montaña and F.P. Montaña, 2001. Introducción a la Fluidoterapia. In: Aplicaciones de Fluidosen Veterinaria, Rejas J., L.E. Fidalgo, A. Goicoa and J.R. González (Eds.), Consulta de Difusión Veterinaria, Valencia, Spain, pp: 53-64.
Sen, I., V. Altunok, M. Ok, A. Coskun and P.D. Constable, 2009. Efficacy of oral rehydration therapy solutions containing sodium bicarbonate or sodium acetate for treatment of calves with naturally acquired diarrhea, moderate dehydration and strong ion acidosis. J. Am. Vet. Med. Assoc., 234: 926-934. DOI: $10.2460 /$ javma.234.7.926

Silanikove, N., 1991. Effects of oral, intraperitoneal and intrajugularrehydrations on water retention, rumen volume, kidney function and thirst satiation in goats. Comparative Biochem. Physiol. Part A: Physiol., 98: 253-258.

Smith, G.W., 2009. Treatment of calf diarrhea: Oral fluid therapy. Vet. Clin. North Am. Food Anim. Pract., 25: 55-72.

Smith, G.W. and J. Berchtold, 2014. Fluid therapy in calves. Vet. Clin. North Am. Food Anim. Pract., 30: 409-427. DOI: $10.1016 /$ j.cvfa.2014.04.002

Suzuki, K., T. Kato, G. Tsunoda, S. Iwabuchi and K. Asano et al., 2002. Effect of intravenous infusion of isotonic sodium bicarbonate solution on acidemic calves with diarrhea. J. Vet. Med. Sci., 64: 1173-1175.

Trefz, F.M., A. Lorch, M. Feist, C. Sauter-Louis and I. Lorenz, 2012a. Metabolic acidosis in neonatal calf diarrhea-clinical findings and theoretical assessment of a simple treatment protocol. J. Vet. Internal Med., 26: 162-170. DOI: 10.1111/j.1939-1676.2011.00848.x

Trefz, F.M., A. Lorch, M. Feist, C. Sauter-Louis and I. Lorenz, 2012b. Metabolic acidosis in neonatal calf diarrhea-Clinical findings and theoretical assessment of a simple treatment protocol. J. Vet. Internal Med., 26: 162-170. DOI: 10.1111/j.1939-1676.2011.00848.x

Tufani, N.A., D.M. Makhdoomi and A. Hafiz, 2013. Rumen acidosis in small ruminants and its therapeutic management. Iran. J. Applied Anim. Sci., 3: 19-24.

Walker, P.G., P.D. Constable, D.E. Morin, J.K. Drackley and J.H. Foreman et al., 1998. A reliable, practical and economical protocol for inducing diarrhea and severe dehydration in the neonatal calf. Canad. J. Vet. Res., 62: 205-213.

Zurita, L., P. Smith and L. Zurich, 1987. Diarrea del terneroreciénnacido. Monografías de Med. Vet., 9: 1-16. 